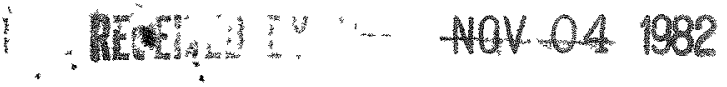

NUREG/CR-2472

BMH-2095

\title{
Final Report on Shipping-Cask Sabotage Source-Term Investigation
}

Prepared by E. W. Schmidt, M. A. Walters, B. D. Trott, J. A. Gieseke

Battelle Columbus Laboratories

Prepared for

U.S. Nuclear Regulatory

Commission 


\section{NOTICE}

This report was prepared as an account of work sponsored by an agency of the United States Government. Neither the United States Government nor any agency thereof, or any of their employees, makes any warranty, expressed or implied, or assumes any legal liability of responsibility for any third party's use, or the results of such use, of any information, apparatus, product or process disclosed in this report, or represents that its use by such third party would not infringe privately owned rights.

\section{Availability of Reference Materials Cited in NRC Publications}

Most documents cited in NRC publications will be available from one of the following sources:

1. The NRC Public Document Room, $1717 \mathrm{H}$ Street, N.W. Washington, DC 20555

2. The NRC/GPO Sales Program, U.S. Nuclear Regulatory Commission, Washington, DC 20555

3. The National Technical Information Service, Springfield, VA 22161

Although the listing that follows represents the majority of documents cited in NRC publications, it is not intended to be exhaustive.

Referenced documents available for inspection and copying for a fee from the NRC Public Document Room include NRC correspondence and irternal NRC memoranda; NRC Office of Inspection and Enforcement bulletins, circulars, information notices, inspection and investigation notices; Licensee Event Reports; vendor reports and correspondence; Commission papers; and applicant and licensee documents and correspondence.

The following documents in the NUREG series are available for purchase from the NRC/GPO Sales Program: formal NRC staff and contractor reports, NRC-sponsored conference proceedings, and NRC booklets and brochures. Also available are Regulatory Guides, NRC regulations in the Code of Federal Regulations, and Nuclear Regulatory Commission /ssuances.

Documents avallable from the National Technical Information Service include NUREG series reports and technical reports prepared by other federal agencies and reports prepared by the Atomic Energy Commission, forerunner agency to the Nuclear Regulatory Commission.

Documents available from public and special technical libraries include all open literature items, such as books, journal and periodical articles, and transactions. Federal Register notices, federal and state legislation, and congressional reports can usually be obtained from these libraries.

Documents such as theses, dissertations, foreign reports and translations, and non-NRC conference proceedings are available for purchase trom the organization sponsoring the publication cited.

Single copies of NRC drafe reports are available free upon written request to the Division of Technical Information and Document Control, U.S. Nuclear Regulatory Commission, Washington, DC 20555.

Copies of industry codes and standards used in a substantive manner in the NRC regulatory process are maintained at the NRC Library, 7920 Norfolk Avenue, Bethesda, Maryland, and are available there for reference use by the public. Codes and standards are usually copyrighted and may be purchased from the originating organization or, if they are American National Standards, from the American National Standards Institute, 1430 Broadway, New York, NY 10018. 


\section{DISCLAIMER}

This report was prepared as an account of work sponsored by an agency of the United States Government. Neither the United States Government nor any agency Thereof, nor any of their employees, makes any warranty, express or implied, or assumes any legal liability or responsibility for the accuracy, completeness, or usefulness of any information, apparatus, product, or process disclosed, or represents that its use would not infringe privately owned rights. Reference herein to any specific commercial product, process, or service by trade name, trademark, manufacturer, or otherwise does not necessarily constitute or imply its endorsement, recommendation, or favoring by the United States Government or any agency thereof. The views and opinions of authors expressed herein do not necessarily state or reflect those of the United States Government or any agency thereof. 


\section{DISCLAIMER}

Portions of this document may be illegible in electronic image products. Images are produced from the best available original document. 
NUREG/CR-2472

BMI-2095

RT, RS

\section{Final Report on Shipping-Cask Sabotage Source-Term Investigation}

MUREG/CR -2472

DEQ3 900255

Manuscript Completed: September 1982

Date Published: October 1982

\section{Prepared by}

E. W. Schmidt, M. A. Walters, B. D. Trott, J. A. Gieseke

Battelle Columbus Laboratories

$505 \mathrm{King}$ Avenue

Columbus, OH 43201

\section{Prepared for}

Division of Risk Analysis

Office of Nuclear Regulatory Research

U.S. Nuclear Regulatory Commission

Washington, D.C. 20555

NRC FIN B6012 and B6710

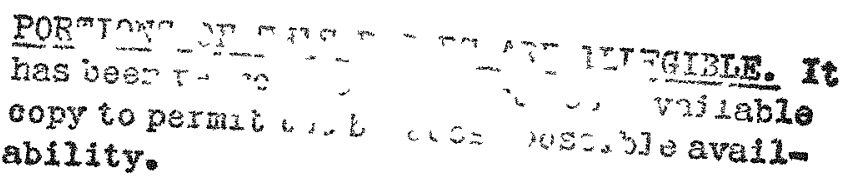


CHAPTER 1. INTRODUCTION............................ 1

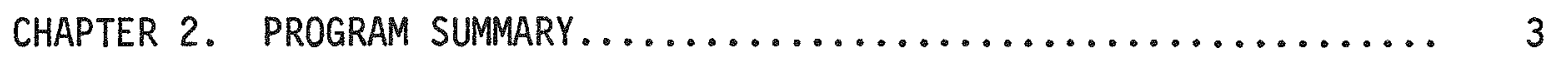

Direct Violations Program......................... 3

Secondary Violations Program.................... 5

CHAPTER 3. DESCRIPTION OF HOT EXPERIMENTS................... 10

Experimental System..................... 10

Detonation Sphere........................ 10

Valves................................... 12

Cave..................................... 12

Sampling Chamber......................... 12

Cask/Fuel Pin Assembly........................ 16

Stopblock and Cradle......................... 19

Sampling Devices.......................... 19

Rupture Disk and Expansion Tank............... 21

Experimental Procedure.................... 22

Pre-Test Activities...................... 22

Test...................................... 24

Post-Test............................... 24

CHAPTER 4. ANALYSIS PROCEDURE...................... 26

Mass of Spent Fuel on Sampling Devices............. 26

Disproportionation of Fission Products.............. 32

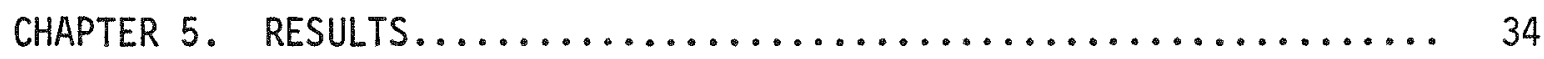

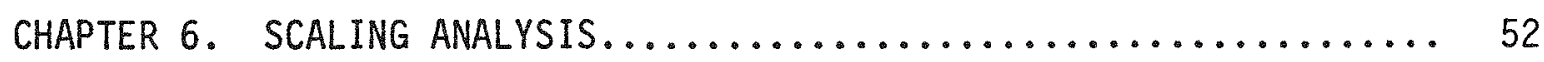

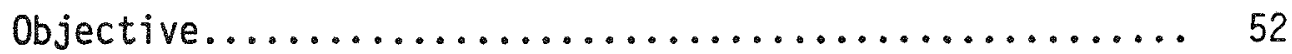

Basic Premise for Scaling.................... 52

Technical Discussion.......................... 53

Analys is of Reference Basis Threat............... 62

Analys is of Subscale Precision Threat............... 66

Application to Scaling.......................... 67

CHAPTER 7. IMPLICATIONS OF RESULTS..................... 73

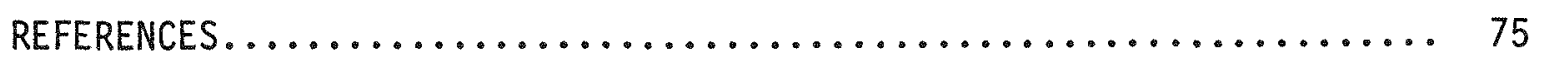




\section{INTRODUCTION}

In recent years concern about the possibility of sabotage of spent nuclear fuel shipments has grown. Studies have indicated that a sabotage attack could have severe consequences. However, those studies used estimated source terms, that is, estimated amounts of radioactive material released from the cask with assumed chemical and physical forms. Because there was no experimental verification of that source term estimate, the consequence calculations which depend directly on the source term selected had a high degree of uncertainty.

To begin development of the necessary data base, the U.S. Nuclear Regulatory Commission (NRC) sponsored a Shipping Cask Sabotage Source Term Investigation at Battelle's Columbus Laboratories (BCL). The objective of the investigation was to characterize the source term produced by a direct violation of a shipping cask. (A direct violation is said to occur when a weapon breaches a cask and radioactive material is released at the point of attack.) In this three-phase program, source term data were collected on direct violations by firing a precision shaped charge at a model cask and analyzing the material that escaped from the cask. The first phase of the program, discussed in the "Interim Report on Shipping Cask Sabotage Source Term Investigation" (1)* (November, 1979), included definition of the reference basis event, analysis of scaling techniques used in making the models, and design of experiments and equipment. Phase Two consisted of experimental design, equipment fabrication, validation of performance of the experimental system's components, and "cold tests" in which the model cask was loaded with cold (unirradiated) fuel rod segments made of depleted $\mathrm{UO}_{2}$. The results of Phase Two are presented in "Topical Report on Shipping Cask Sabotage Source Term Investigation"(2) (November, 1981).

The results of Phase Three are presented in this report. In Phase Three, the experimental design and techniques developed in the first two phases of the program were applied to the collection of source term data on direct violation of model casks containing spent fuel rod segments. Chapter 2 of this report is a program summary outlining all phases of the shipping

* References are listed at the end of this report. 
cask sabotage source term studies carried out at BCL. Chapter 3 describes the hot experiments performed in Phase Three, and Chapter 4 presents the data analysis procedures. Results of the direct violation experiments are reported in Chapter 5, and the scaling analysis used to relate the experimental results to a full scale event is presented in Chapter 6 . Chapter 7 discusses the implications of the results.

It should be noted that after the program to characterize the source term from a direct violation was underway, BCL was selected to conduct a closely related program entitled "Source Term Characterization Resulting From Explosively Caused, Secondary Violations of Spent Fuel Shipping Casks". The secondary violations program was conducted because there was concern that a significant source term might result if an explosive device deformed a shipping cask, failing the cask closures and allowing spent fuel to be ejected. Preliminary results of the secondary violations investigation will be discussed in Chapter 2 of this report, along with the summary of the direct violations program. 
CHAPTER 2

PROGRAM SUMMARY

Two closely related programs were conducted to characterize the source terms resulting from a sabotage attack on a spent fuel shipping cask. The first program focused on direct violations while the second program investigated secondary, or indirect, violations. This chapter will present an overview of both programs.

\section{Direct Violations Program}

The objective of the direct violations program was to characterize the source term released when a loaded spent fuel shipping cask is breached at the point of attack. The program was conducted in three phases: (1) definition of reference basis event, scaling analysis, and design of experiments and equipment; (2) validation tests and cold tests; and (3) hot tests and data analysis and interpretation.

Phase One began with the definition of the reference basis event. It was necessary to identify the combination of threat (weapon), cask, and fuel which would produce the potentially most hazardous, yet realistic, source term. The chosen threat was an $M-3$ conical shaped charge. It appeared to be capable of both penetrating the cask and shattering the fuel into respirable particles. Therefore, it is a realistic choice for use in sabotage. The shipping cask selected was a generic air-cooled, lead-shielded steel container typically used in the United States. Pressurized water reactor (PWR) fuel with a burnup of 33,000 MWD/MTHM and a five-year cooling period was chosen as the reference fuel, because this type of fuel contained the fission products of interest and appeared most likely to be shipped.

Designing the experiments was the next step. Full-scale tests with irradiated fuel were clearly impractical because they would be both expensive and dangerous, so laboratory scale experiments were chosen. In these experiments, a subscale shaped charge was fired through a small cask/fuel pin assembly; 
sampling devices were used to determine the amount and particle size distribution of the spent fuel released; and scaling laws were applied to the results to estimate the release from a full scale event. The experimental design also provided for a number of preliminary tests to verify that the experiments would yield adequate data and could be conducted safely.

The final task in Phase One was to design the equipment. The experimental system initially consisted of two chambers, a detonation sphere and a sampling chamber, separated by an explosively-actuated, fast-closing isolation valve. A shaped charge was detonated in the sphere; its jet passed through the open isolation valve into the sampling chamber; and the valve closed immediately after the jet passed keeping detonation product gases in the sphere. Within the sampling chamber there were many other important pieces of equipment including the cask/fuel pin assembly, the stopblock which arrested the jet after it penetrated the model cask, and three different types of sampling devices.

After the experiments and equipment were designed, the construction and testing of the system (Phase Two) began. First, validation tests were done on individual components and groups of components, and then cold tests were conducted using the assembled system.

Dozens of validation tests were done to insure that each component worked properly and that it was compatible with the rest of the system. Most tests were quite simple, but four types required extensive planning. They were: (1) shaped charge jet characterization, (2) isolation valve timing, (3) system overpressure measurement, and (4) jet-fuel pin interaction. The shaped charge jet characterization tests indicated the thickness of steel required to stop the jet and the time needed for the jet to pass through the isolation valve. Valve timing experiments determined the delay between charge detonation and valve actuation and demonstrated that the valve did indeed close quickly enough to keep detonation gases in the sphere. Jetfuel pin interaction tests verified that the cask/fuel pin design was adequate. The only validation test that did not support earlier calculations was the overpressure test. It showed the system's normal operating pressure to be about $18 \mathrm{psig}$, much greater than expected, and the pressure when the explosive valve failed to be about $142 \mathrm{psig}$. To ensure safety, the sampling chamber was redesigned to withstand a pressure of $80 \mathrm{psig}$, four times as great as the anticipated operating pressure. In addition, an eight-inch 
diameter pipe was run from the samp1ing chamber to a 5-cubic-meter expansion tank, and a rupture disk was placed in the pipe near the sampling chamber wa11. With the rupture disk and expansion tank installed, pressure in the system would never be high enough to rupture the sampling chamber, and no radioactive material would be released from the experimental system.

After validation tests were satisfactorily completed, the system was assembled and cold tests were run to demonstrate that the system performed as expected. The cold tests were identical to the final experiments except that depleted $\mathrm{UO}_{2}$ was used in the fuel pins instead of spent fuel. Results of those tests were presented in Reference 2.

Phase Three consisted of hot tests and data analysis. In each test, a precision shaped charge was fired through a model cask containing segments of a spent PWR fuel rod. The radioactive material released from the cask was collected with three types of sampling devices and then analyzed to determine how much material was released, the isotopic composition of that material, and its particle size distribution. These hot experiments are the subject of this report.

\section{Secondary Violations Program}

The secondary violations program was designed as a complement to the direct violations program. Because the results of the secondary violations program were unexpectedly straightforward, it seems desirable to outline those results here, in order to provide as full a description as possible of the effects of explosive devices on shipping casks. Preliminary studies in the direct violations program indicated that a shaped charge would disperse more respirable radioactive material than any other common weapon. There was, however, a concern that other types of explosive devices might deform a shipping cask, causing the cask closures to fail and pushing portions of the spent fuel element out of the cask. There was also some interest in experimentaliy verifying that the shaped charge did indeed produce more respirable material than other weapons.

As in the direct violations program, full scale tests with irradiated fuel were impractical. Furthermore, the nature of explosive devices to be tested precluded their use in a hot cell. Thus, spent fuel could not be used. 
The above constraints were recognized before the program was proposed and were taken into account in its planning. Because spent fuel could not be used, one of the first tasks was to identify a suitable surrogate. Other preliminary tasks included: (1) evaluation of several explosive devices and selection of two or three expected to have the greatest effect on the cask; (2) evaluation of cask designs; (3) development of scaling laws; and (4) completion of the experimental design.

Depleted $\mathrm{UO}_{2}$ was chosen as the surrogate fuel. Four criteria were established for surrogate fuel selection: (1) density similar to that of spent fuel, (2) fracture characteristics similar to those of spent fuel, (3) readily available or easily fabricated, and (4) safe. Depleted $\mathrm{UO}_{2}$ obviously met criteria 1 and 3. A series of experiments confirmed that it met criterion 2 and calculations verified that it met 4.

Next, several casks were evaluated and it was determined that a generic lead-shielded, water-jacketed steel cask would be used. It was decided that the model casks used in the experiments should be as close to one-eighth and one-quarter scale as practical, using off-the-shelf materials when possible.

Explosive devices considered included a breaching charge, a platter charge, and an air blast. Earlier studies at another laboratory had shown on water-jacketed scale model casks that a reference basis breaching charge would be expected to cause only minor damage. This work had also shown the validity of the scale model approach using straight geometric scaling in dealing with these threats, when the models faithfully reproduced the full-scale cask material properties. The lack of critical damage produced by the breaching charge is related to the charge decoupling effect produced by the circumferential water jacket which is present on all current-day cask designs. Similar tests had not been conducted on water-jacketed cask models using the platter and air blast charges; consequently, only the platter charge and air blast were included in the secondary violations experiments. The NRC specified the size and explosive content of the reference basis threat. 
While these preliminary tasks were being conducted, work continued on the experimental design. Briefly, each experiment was to consist of detonating an explosive device near a subscale cask loaded with depleted $\mathrm{UO}_{2}$ fuel rods and then characterizing the material released from the cask. Because these tests were to determine an attack's effects on the cask wall and the endcaps, the subscale models to be used in the final tests needed to be exact replicas of the full-scale casks. The experimental design also included some preliminary tests to be done with less accurately modeled casks to provide information for "fine tuning" the procedures in the final experiments.

The preliminary tests consisted of attacking a one-eighth scale cask with a similarly scaled platter charge and another with an air blast. Figures 2.1 and 2.2 show the damage done to the model casks by the platter charge and air blast, respectively. 


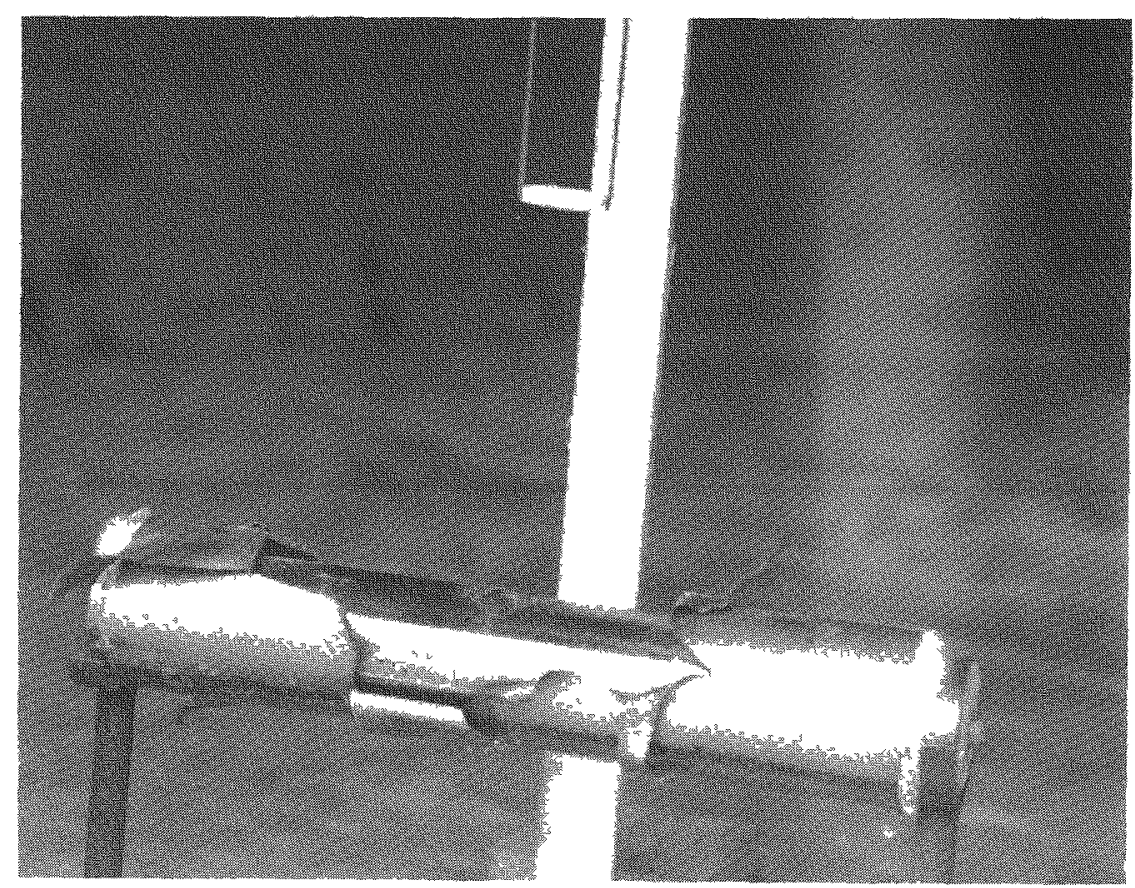

Figure $2-12$

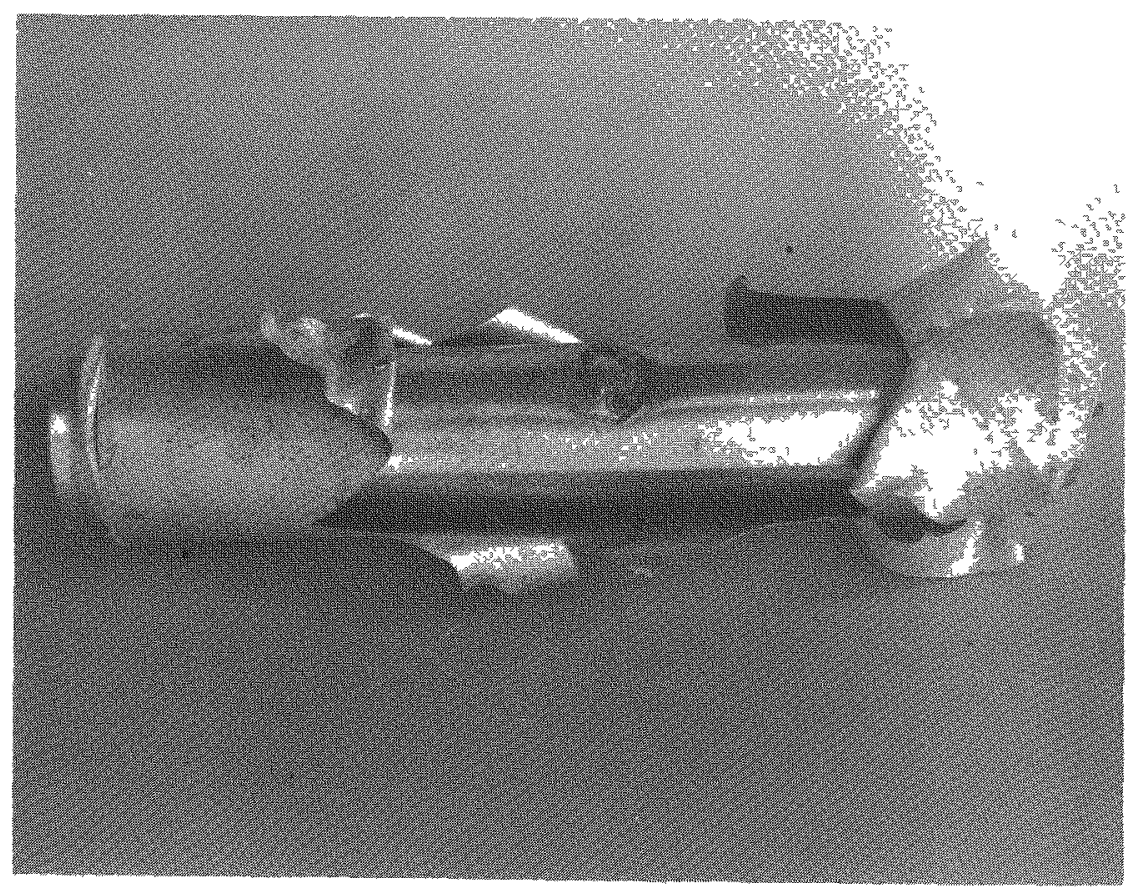

Figure $2-7 b$

FIGURE 2-1. MODEL CASK ATTACKED WITH PLATTER CHARGE

Figure 2-1a shows how the platter charge was oriented with respect to the cask.

Figure 2-1b is a better view of the damage done by the platter charge. 


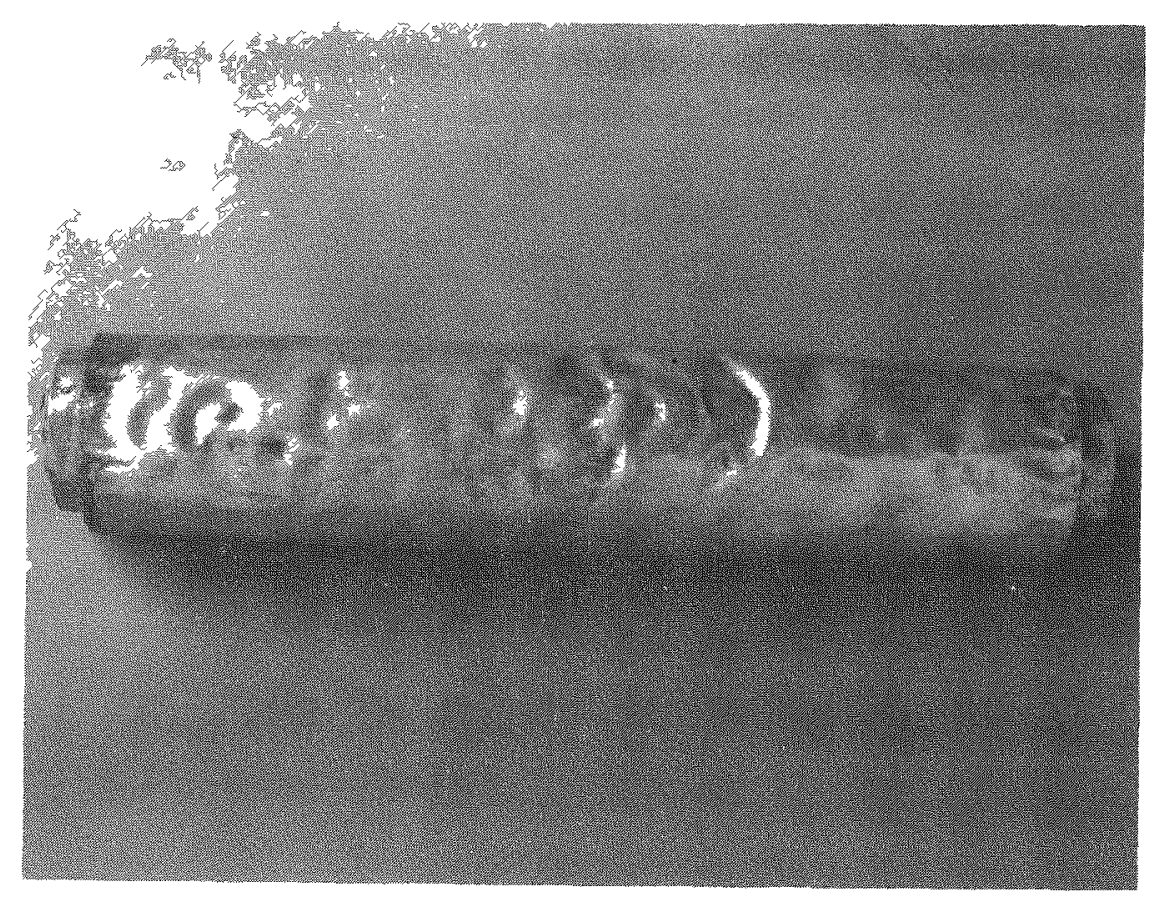

Figure 2-2a

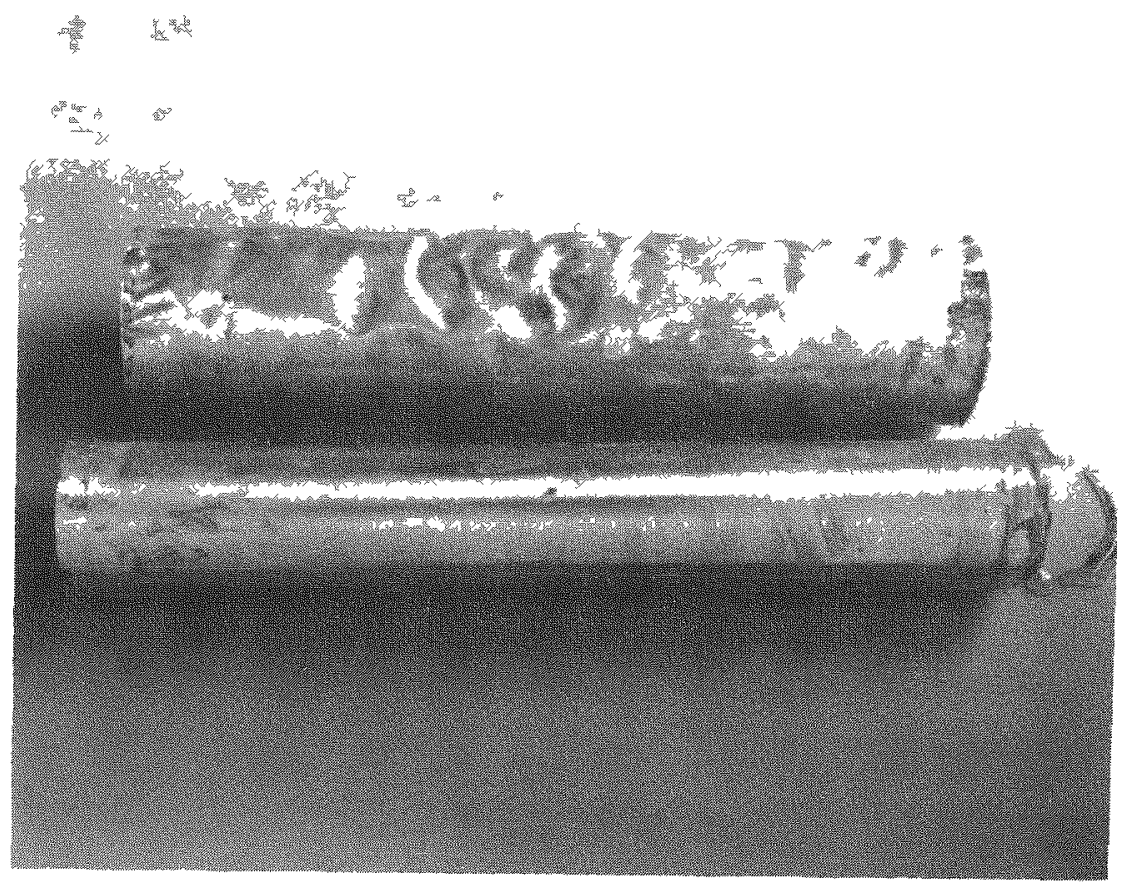

Figure $2-2 b$

FIGURE 2-2. MODEL CASK ATTACKED WITH AN AIR BLAST

Figure $2-2 a$ shows the cask immediately after the shot.

Figure $2-2 b$ shows the water jacket and the cask that has been removed from the jacket. 
CHAPTER 3

\section{DESCRIPTION OF HOT EXPERIMENTS}

The final phase of the direct violations program was devoted to hot tests. These experiments consisted of firing a shaped charge through a model cask loaded with spent PWR fuel rod segments and characterizing the material released from the cask. For the first six hot tests, the system and the sampling procedure were the same as those used in the cold tests. The system and procedure are described briefly here and in more detail in Reference 2. For the last two hot shots, the sampling system was slightly modified. Details of the modifications are presented in this chapter.

\section{Experimental System}

The experimental system for the hot tests utilized three chambers, a detonation sphere to contain the blast, a sampling chamber to confine and allow measurement of the radioactive material, and an expansion tank to provide for safe containment of all radioactive material in the event of a failure in the isolation valve. These three chambers were connected by various devices to complete a sealed system. Figure 3-1 shows this system schematically.

\section{Detonation Sphere}

The detonation chamber, a hollow steel sphere $3 \mathrm{ft}$. in diameter with 1-in. thick walls, was obtained from Los Alamos Scientific Laboratory with the assistance of Mr. William R. Field of LASL. The 16-in. port on top of the sphere was used for access to mount and aim the shaped charge. An 8-inch port cover on the right side of the sphere (as viewed in Figure 3-1) provided a place to mount the shaped charge support assembly inside and the explosively-actuated valve on the outside. A 2-in. hole in this cover allowed passage of the shaped charge jet. The other 8-in. port was fitted with a cover equipped with a high voltage lead-through for the detonator, an electrical terminal for the detonator circuit, and a through hole for the pressure relief valve. 


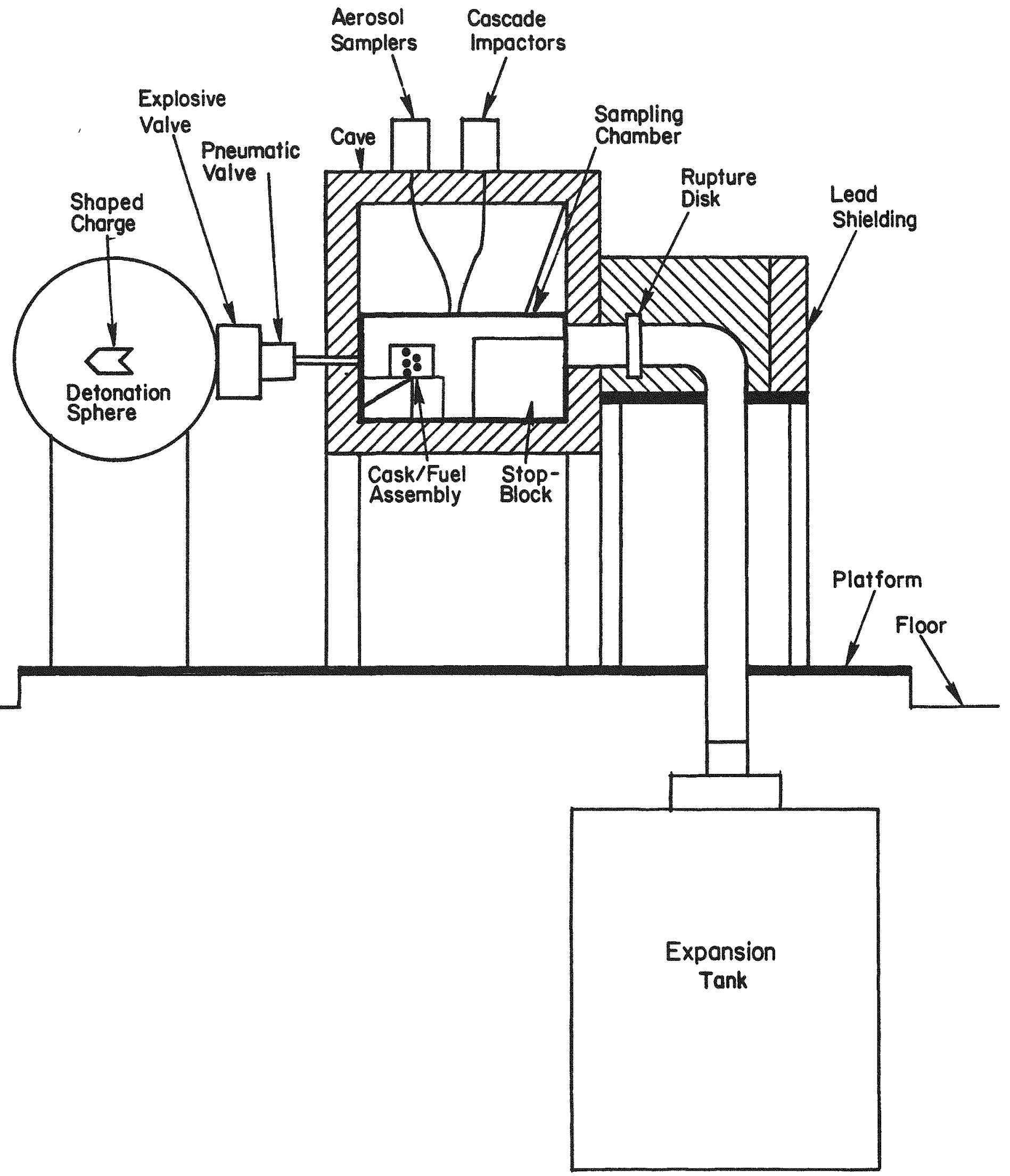


Valves

After the shaped charge jet left the detonation sphere, it passed through two valves, one explosively actuated and one pneumatically actuated. In the explosive valve, a soft, tapered aluminum piston was driven by an explosive charge into a tapered hole in the steel body to form an airtight seal. The valve closed in approximately 500 microseconds. Its function was to keep detonation gases in the sphere and radioactive material in the sampling chamber. The pneumatic valve closed much more slowly, in slightiy less than one second, and served to seal the sampling chamber while the explosive valve was changed between shots.

Cave

The cave housed the sampling chamber and shielded personnel from radiation emitted by spent fuel in the model casks. It was a 4-foot cube with 4-inch-thick lead walls and floor and a 2-inch-thick steel top. A $22 \mathrm{in.} \times 17 \mathrm{in} . \times 8 \mathrm{in}$. lead glass window in the front wall allowed observation of work inside. Two mechanical arms were installed through the top of the cave for handling radioactive material. Figure 3-2 is a picture of the experimental system, showing the cave, detonation sphere and valves.

\section{Sampling Chamber}

The heart of the experimental system was the sampling chamber. Figure 3-3 is a cut away diagram of the chamber, and Figure 3-4 is a picture of it. Its function was to confine radioactive material disrupted by the shaped charge jet and to allow sampling of that material. A number of components housed in or attached to the chamber helped it perform its function.

The chamber itself was a $34 \mathrm{in} . \times 34 \mathrm{in} . \times 15 \mathrm{in}$. stainless steel box with one-inch thick walls and a number of penetrations. A list of those penetrations will be helpful in understanding the operation of the chamber. The left wall, as viewed in Figure 3-4, contained a two-inch I.D. pipe 


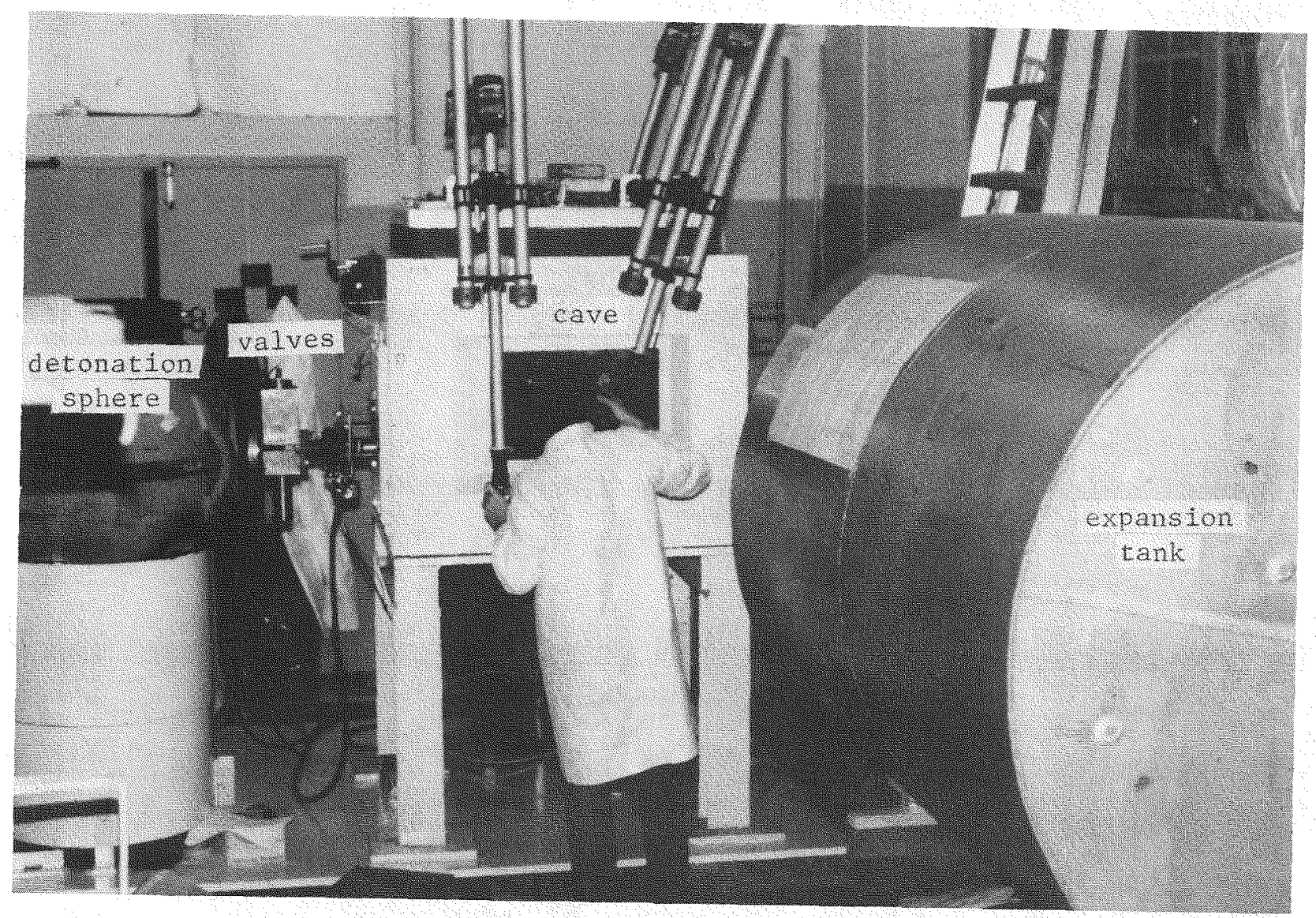

FIGURE 3-2. EXPERIMENTAL SYSTEM 


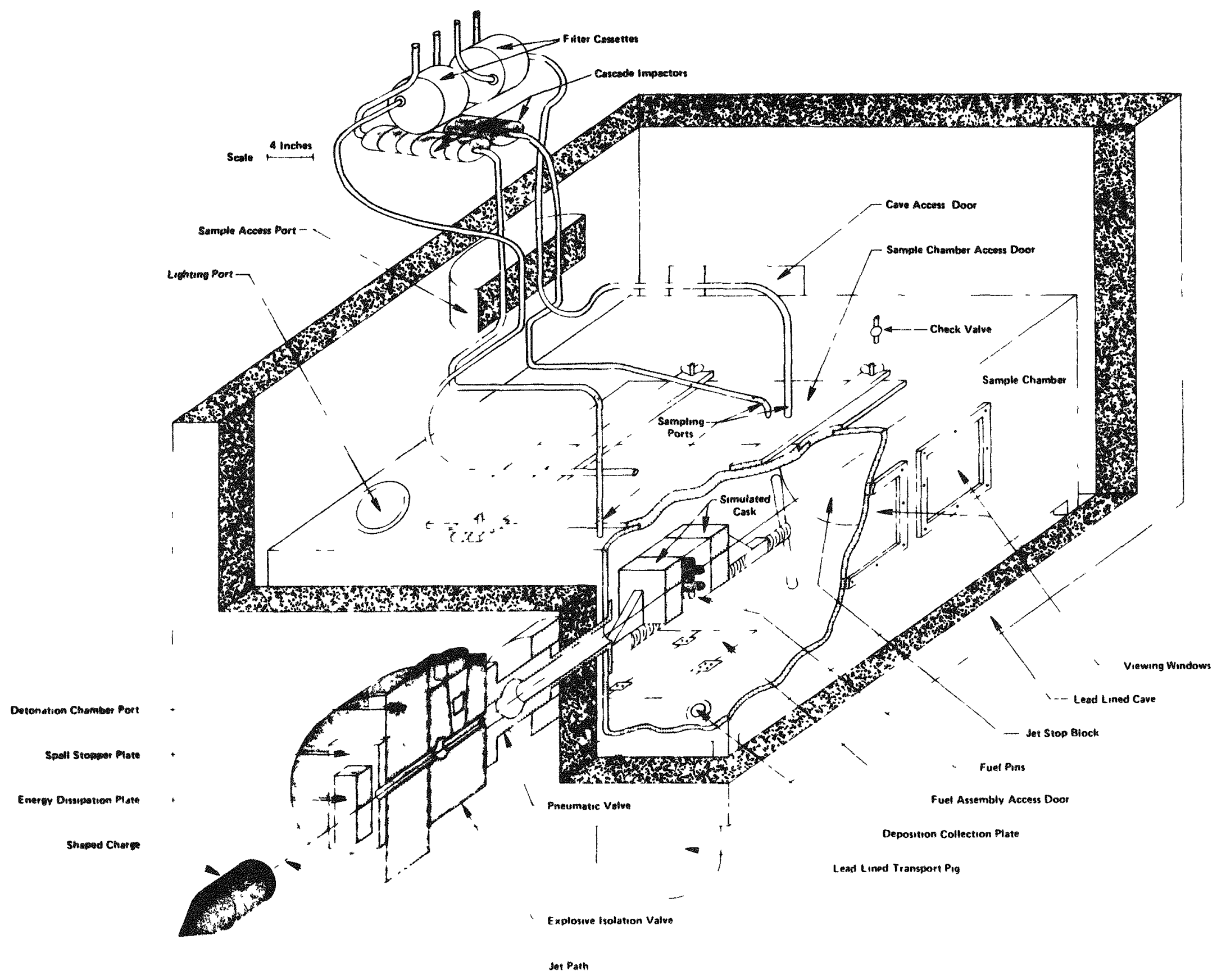




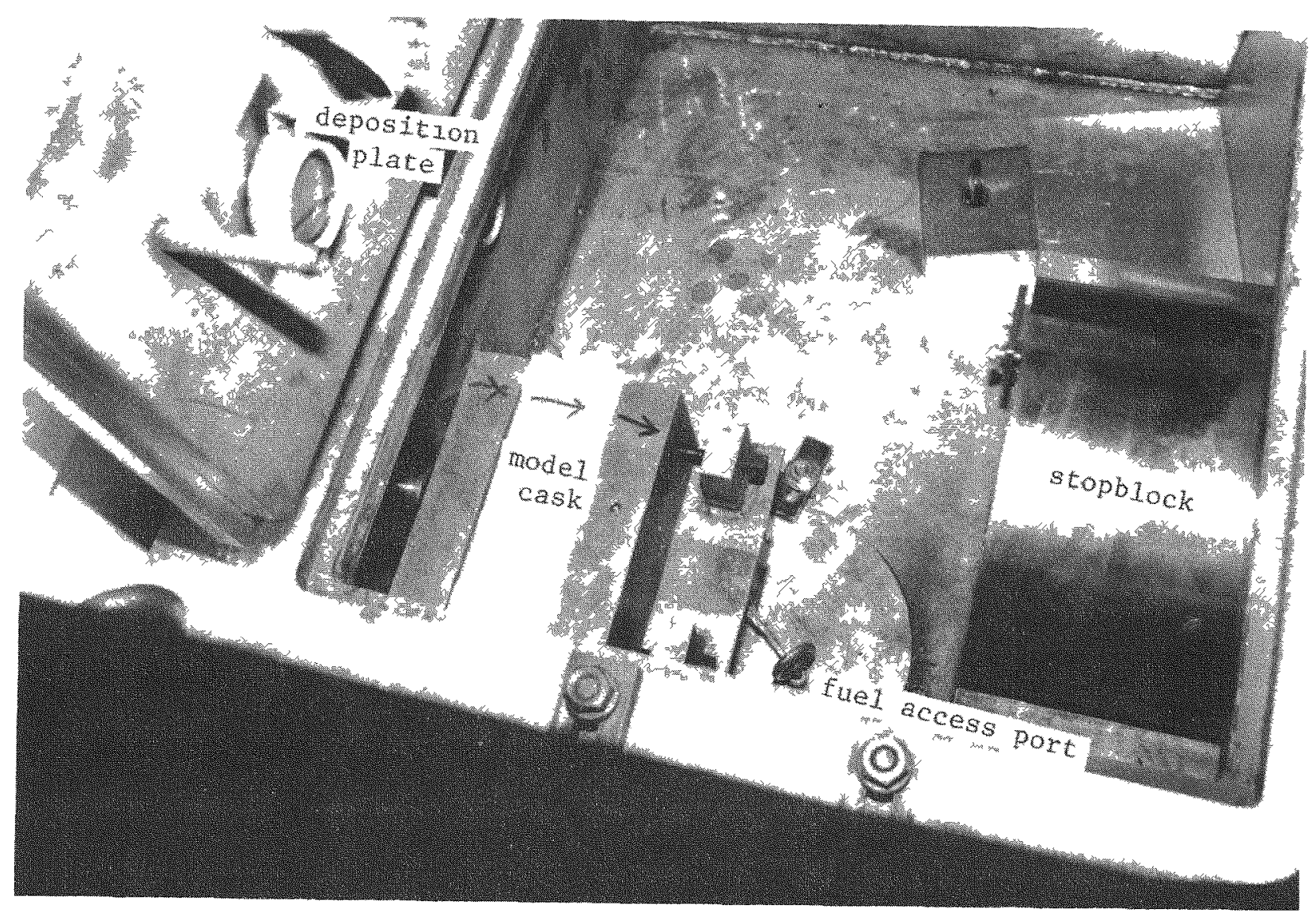

FIGURE 3-4. INTERIOR VIEW OF SAMPLING CHAMBER 
through which the shaped charge jet traveled. The front wall had a viewing window designed to match the one in the cave. Three penetrations were made through the right wall. One was fitted with a glass plug that admitted a laser beam used to align the shaped charge. Another, 8 inches in diameter, was fitted with a pipe that housed a rupture disk. The third was for a pressure transducer. The penetration in the bottom of the chamber was a six-inch diameter port through which the cask/fuel pin assembly was delivered. Six penetrations were made in the top of the box. The largest was the door which is shown open in Figure 3-4. It was large enough to allow the mechanical arms mounted in the top of the cave to perform necessary tasks in the chamber. A second penetration in the chamber's top was a 5-1/2 in.-diameter 1ighting port. Four other penetrations were $1 / 2-i n$. sampling ports--two in the door that permitted sampling of the air behind the cask and two in the ceiling that permitted sampling in front of the cask. Associated with the sampling chamber were three subsystems: (1) the cask/fuel pin assembly and its support, (2) the stopblock and cradle, and (3) the sampling system consisting of three types of collection devices. Each of these subsystems is described in the following paragraphs.

Cask/Fuel Pin Assembly

A typical cask/fuel pin assembly is pictured in Figure 3-5. It consists of two outside walls made of $1-3 / 4 \times 4 \times 8$-in. steel blocks and a central core made of $3 \times 4-i n$. rectangular steel tubing with steel plates welded on each end. Five segments of spent fuel rod were placed in the core of the cask. The plugs in the holes drilled to admit the pins to the cask are visible in the endplate shown in Figure 3-5. Figure 3-6 is a diagram of the cask core showing how the fuel pins are supported inside the structure*.

To make each surrogate fuel pin, a 7-inch length was cut from a spent fuel rod. From each end $1-1 / 2$ inches of fuel were removed, taking care not to disturb the 4 inches of fuel remaining at the center of the pin. Steel plugs $1-1 / 2$ inches long were put in each end in place of the removed fuel. Reasons for the choice of length of pin, amount of fuel in each pin and configuration of the five pins are given in References 1 and 2.

Note that for these tests, the cask was air-filled rather than waterfilled because air-filled casks are more commonly used now and filling the casks with water might have significantly reduced the aerosol released. 


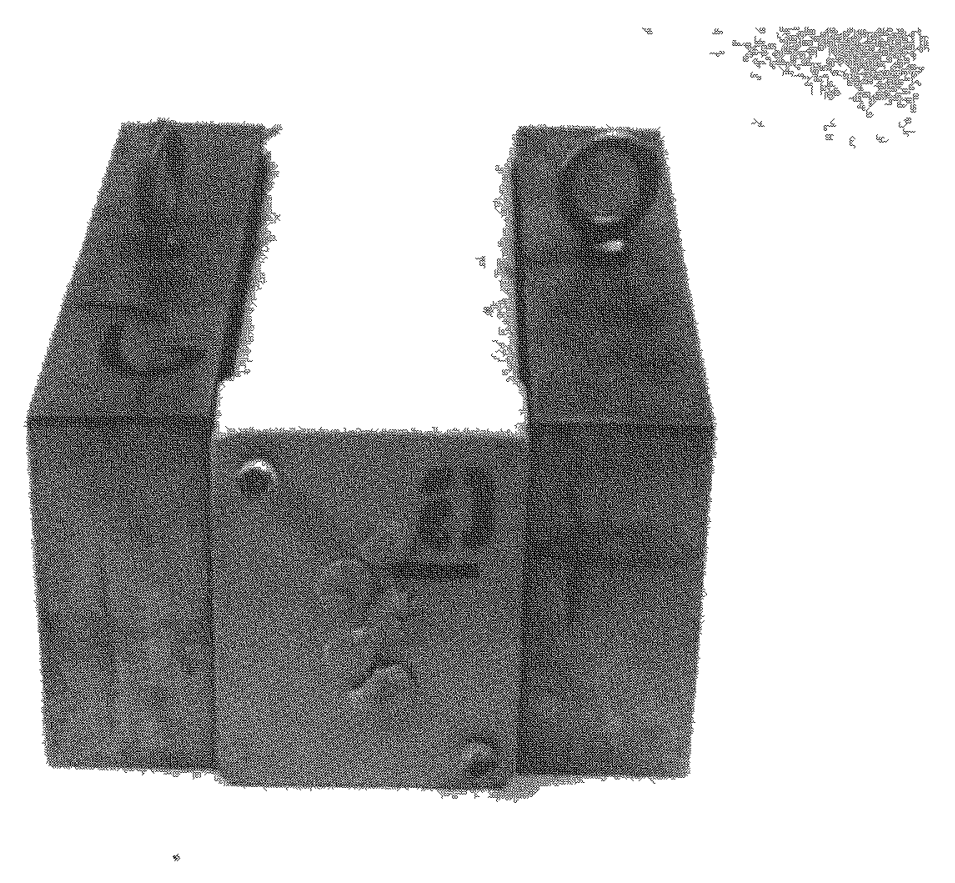

FIGURE 3-5. CASK/FUEL PIN ASSEMBLY 

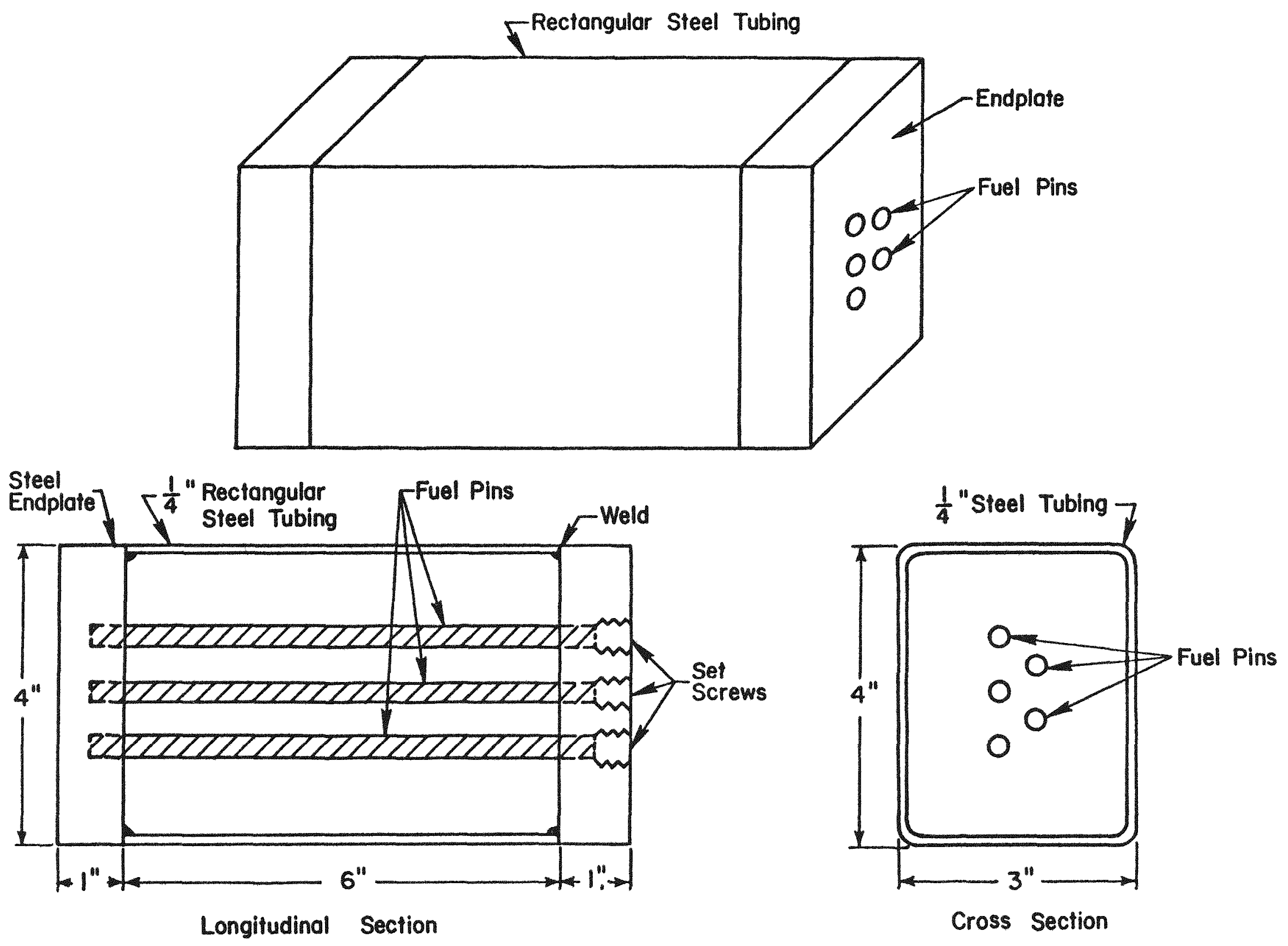

FIGURE 3-6. MODEL CASK DESIGN 
Although each of the eight hot tests used the same type and configuration of fuel pins, three different types of cask were used. The first two shots used a full cask like the one shown in figure 3-5. The next two shots were conducted with a half cask which had no back wall. In tests five and six, a no cask configuration, one with no cask walls, was used. The final two shots were conducted with full casks like those used in tests one and two. These three types of cask are diagramed in Figure 3-7. As a safety precaution, when a half cask was used, a plate of steel with thickness equal to that of a cask wall was placed in front of the stopblock. In a no cask test, two plates of steel were put in front of the stopblock. Thus, the shaped charge jet always travelled through the same thickness of steel.

\section{Stopblock and Cradle}

The stopblock, a 16 in. $x 12$ in. diameter steel cylinder, was mounted in a cradle on roller bearings so that it could be rotated to a different position for each shot. The shaped charge was aimed so that it struck the stopblock off center. Thus, several shots could be conducted without replacing the stopblock.

Sampling Devices

Three types of sampling devices were used to characterize the material released from the model cask during an experiment. Two filter cassettes, one sampling air in front of the cask and one sampling behind it, measured total airborne concentrations. Two cascade impactors, again sampling air in front of and behind the cask, measured particle size distribution; and deposition plates located in the sampling chamber collected particles deposited on its interior surfaces. The same cascade impactors were used for all eight tests. Details of the construction and operation of the cascade impactors and of the filter cassettes used for the first six tests are given in Reference 2. Modifications in the filter cassettes and deposition plates for the last two tests are discussed in the following paragraphs.

In the first six tests each sampling port connected to a rotating filter cassette equipped with five filters. The air to be filtered entered 


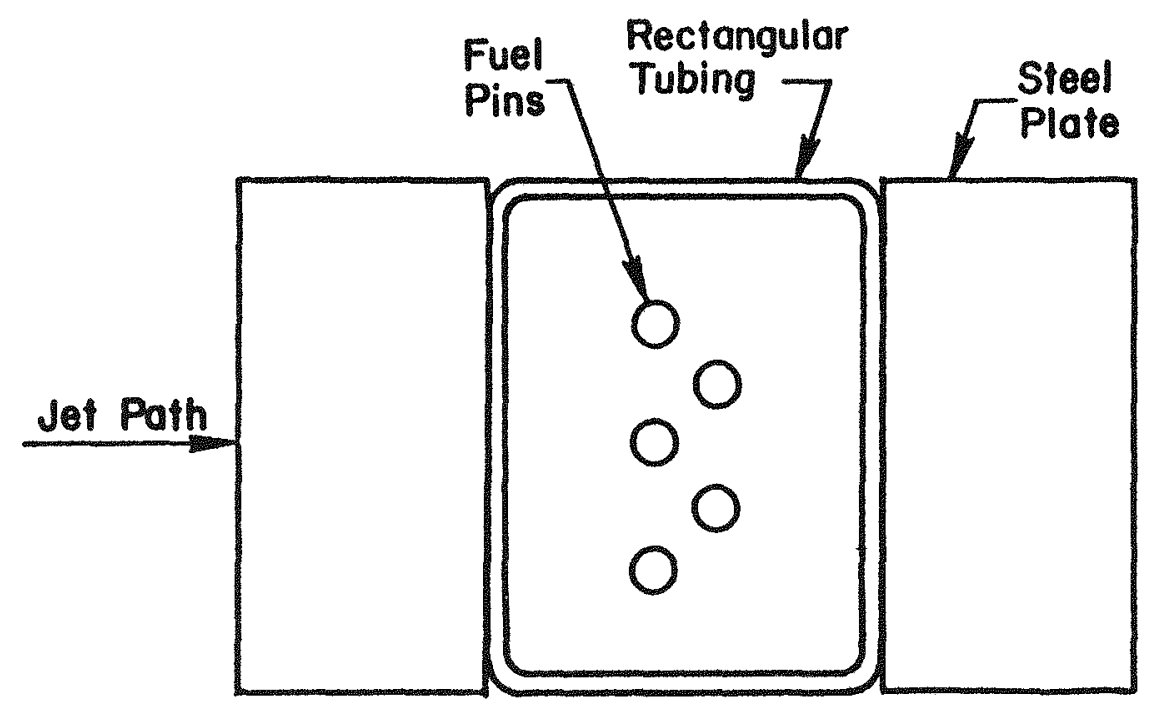

Full Cask

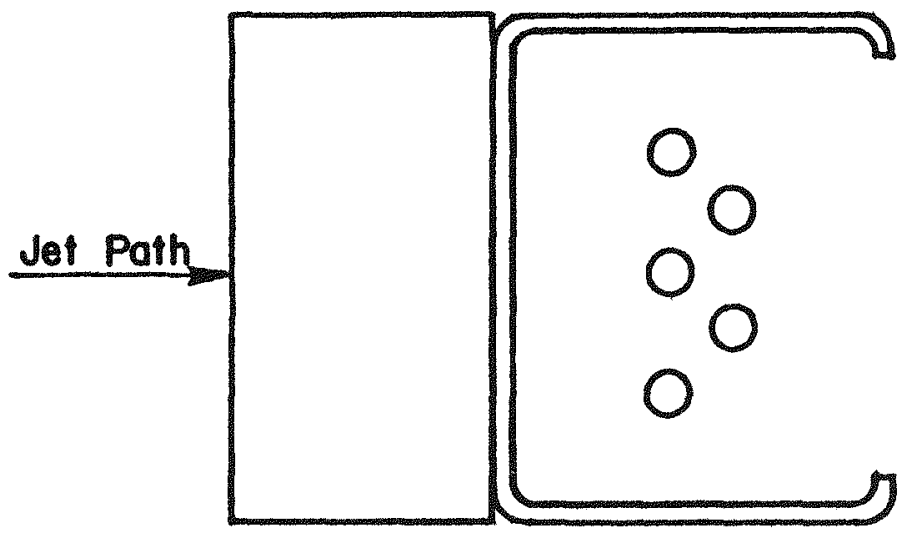

Half Cosk

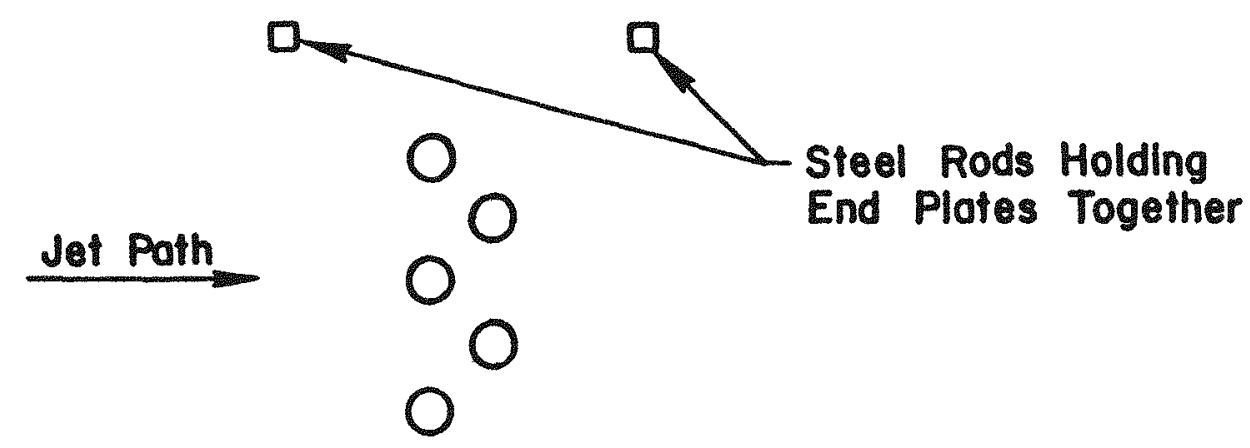

口

口

No Cask

FIGURE 3-7. CROSS SECTIONS OF MODEL CASK GEOMETRIES 
each cassette through one orifice. At the beginning of the sampling, the first filter was over the orifice. When it was time for the second sample to begin, the cassette rotated until the second filter was over the orifice. Although the cassettes rotated as programmed in numerous tests before, between and after the hot shots, they occasionally appeared to rotate incorrectly during the shot; perhaps because of the shock caused by the explosion. In the last two tests, each sampling port was connected through a distribution manifold to five individual filter cassettes. The flow-through to each cassette was controlled by a separate solenoid valve. When the first sample began, the first valve was opened. When it was time to begin the second sample, the first valve was closed and the second one opened. All valves were operated by the computer that controlled the test so as to provide the same sampling time sequence used in the previous six tests.

Nine deposition plates were used in the first six tests. The same nine plus six more plates were used in the last two tests. More plates were employed because the material that leaves the model cask is not uniformly distributed in the sampling chamber, and more plates were required to better characterize the distribution. The six new plates were located as follows: two on the face of the stopblock, two on the table that holds the model cask (one in front of and one behind the cask), and two on the floor beside the table.

Rupture Disk and Expansion Tank

Preliminary experiments showed that if the explosively-actuated valve failed, the pressure in the sampling chamber could reach $142 \mathrm{psig.}$ It was not practical to build a rectangular chamber that could withstand such a pressure with the required safety margin. To ensure safety, the experimental system was modified. An 8-inch diameter hole was cut in the sampling chamber and fitted with an 8-inch pipe that ran to a 5-cubic-meter expansion tank. A rupture disk designed to fail at 20 psig was put in the pipe a few inches from the sampling chamber wal1. Thus, in the event of an explosive valve failure, the rupture disk would break allowing gas to expand into the 5-cubic-meter tank, maintaining the pressure at an acceptable level. 


\section{Experimental Procedure}

Each experiment consisted of three steps: (1) pre-test setup and checkout, (2) test, and (3) post-test data collection and cleanup. Each of the three steps is described in some detail below.

\section{Pre-Test Activities}

The first task was to mount the shaped charge in its alignment fixture inside the detonation sphere and connect the detonator leads to the high voltage electrical lead-through on the sphere. The charge was aligned using the laser/optical method. The experimental system was designed to provide the laser beam a free path to the shaped charge when the valves were opened and the stopblock rotated so that a hole drilled through it was directly in front of the laser. After the charge was aligned, the alignment mirror, which was temporarily attached to the front of the shaped charge, was removed, the large port on the detonation chamber was secured and the stopblock was rotated so that the hole was no longer along the jet's path.

Next, the explosively actuated valve was installed. Because this valve sealed by forcing a tapered aluminum piston into a tapered hole in a steel body, it could be used only once. A new valve was installed for every shot.

Preparing the sampling chamber for the test involved several tasks. First, the cask was brought in through the fuel access port in the bottom of the chamber. Then the port cover was closed and securely fastened, and the cask and cask walls were put on a table and fastened in place. The stopblock was checked once again to be sure that it had been rotated to the correct position and was locked in place. The table holding the cask was secured. Deposition plates were placed in predetermined locations and shields pulled over the rupture disk and window to protect them from shrapnel. Finally, the doors to the sampling chamber were closed and fastened. 
When the work in the chamber was nearly complete, the sampling equipment was tested and a background sample taken. A small computer controlled the operation of the pneumatic valve between the sphere and sampling chamber, the solenoid valves leading to the sampling devices, the pumps that pulled air through those devices, and the devices themselves. The computer program was run and valves, pumps, cassettes, and impactors checked to be sure that they worked properly. One cassette and one cascade impactor were run through the entire sampling sequence to collect a background sample.

Next, the safety systems were checked. A plastic tent was erected around both the cave and the 8-inch pipe running from the cave to the expansion tank and some air was evacuated from it to keep the pressure inside negative. A filter was put in the vent line running from the detonation sphere to the ventilation system. (In the event that the air in the sphere became contaminated, the filter would trap any radioactive material.) All monitors in the room and adjacent working areas were checked, and a sample of air in the room was taken.

Finally, the detonation system was tested. Bridgewires were connected to the firing leads which would eventually be wired to the shaped charge and explosively actuated valve. Current was sent through the bridgewires, and if all was well, they exploded. At that time, the electronic system that recorded the sample chamber pressure during the shot was checked. The last task was to connect the firing leads to the charge and the explosively actuated valve.

When the system was thought to be ready for the test, a detailed checklist was read to be certain that nothing had been overlooked. If no additional work was required, the room was cleared, and people working in the building were warned of the impending explosion. 
Test

The test was conducted under the control of the pre-programmed computer. By using the computer, all of the precisely timed operations were made reproducible from shot to shot. When the program was initiated, the pumps started. Fifteen seconds later, the pneumatically actuated valve opened. After 15 more seconds, a signal from the computer caused one capacitor to detonate the shaped charge and started a 135-microsecond delay generator. At the end of the delay, the second capacitor actuated the explosive valve. At the same time the computer started the detonation sequence, it also de-activated the pneumatic valve, allowing it to close.

Post-Test

Immediately after the shot, solenoid valves in the sampling lines opened and sample collection began. The two cassettes, containing five filters each, operated in tandem. Each of the filters collected airborne material for a prescribed length of time. Filter one was used for 30 seconds, filter two for 30 seconds, and filters 3, 4, and 5 for 1, 3, and 5 minutes, respectively. Both cascade impactors were run for 10 minutes.

After 10 minutes, the pumps shut off. The cassettes and impactors, which were outside of the cave, were disconnected from the sampling lines and taken to a workbench. There the filters and impactor slides were removed and placed in individual, premarked plastic containers. The cassettes and impactors were reloaded and connected to the sampling lines once again.

About 1 hour after the shot, the cassettes and impactors were run again. The timing sequence was the same as the one used during the first run: 30 seconds for each of the first two cassette filters; 7,3 , and 5 minutes for the last three; and 10 minutes for each impactor. After the second run, the filters and glass slides were removed and the sampling devices reloaded. For the first six tests, a third sample was taken the following day, about 18 hours after the shot. Each cassette filter was in use for 5 minutes and each cascade impactor operated for 25 minutes. The filters and impactor slides were removed and stored as before. Very little information 
was gained from that third set of samples, and they were not taken for the last two shots.

After all of the aerosol samples were taken, the chamber was opened and the system dismantled. First, the cask and cask walls were carefully taken out of the chamber. Deposition plates were removed from the chamber and put in individual containers for later analysis. The depth of the hole in the stopblock and radiation levels at various locations in the chamber were measured. The inside of the sampling chamber was washed down with cloths soaked in cleaning solution. The isolation valve was removed and a dose rate read on contact with the aluminum piston that catches material ejected through the jet's entrance hole in the cask. Then detailed analysis began.

Much information was collected from the cask/fuel pin assembly. Pictures were taken of the entrance and exit holes in the cask and both cask walls. If a half cask or no cask configuration was used, pictures were taken of the steel plates that were set in front of the stopblock. The cask was carefully cut open and the fuel pins removed. Each pin was weighed and photographed. By comparing this weight with the initial value, the amount of fuel and cladding disturbed was calculated. All debris that remained in the cask during the shot and any that was shaken from the pins during subsequent handling was collected and weighed. A covered magnet was passed through this debris to remove any steel which may have come from the cask walls, and the debris was weighed again. Using this weight and the combined weight of the pins, the amount of material released from the cask during the shot was calculated.

Analys is of the aerosol samples was the final and most timeconsuming task. It is described in some detail in the following chapter. 


\section{CHAPTER 4}

\section{ANALYSIS PROCEDURE}

\section{Mass of Spent Fuel on Sampling Devices}

One fundamental question had to be answered before analys is of the source term could begin: How much spent fuel was deposited on each sampling device? Several ways to measure the amount of spent fuel on each sampling device were considered, but most had serious drawbacks. One might simply weigh the filter or plate before and after the experiment to determine the amount of material collected. But microgram quantities were involved, and balances capable of weighing such small amounts were not available in the contaminated area where spent fuel was handled. In addition, both steel from the cask walls and spent fuel were collected on the sampling devices. The weight of material would, therefore, include both steel and fuel and yield an inaccurate result. Since the spent fuel was primarily U-238, methods of measuring the amount of that isotope present were suggested. Because of its long half-life, however, U-238 emits no easily counted alpha, beta, or gamma radiation, so radioanalys is was not practical. Uranium fluorescence was used to determine the amount of U-238 collected during the cold tests, but that method was not feasible when highly radioactive spent fuel was involved.

It was decided that the amount of spent fuel present in each sample could best be determined indirectly. A sample of HB Robinson fuel was dissolved and its actinide composition determined in the laboratory. Using information available on HB Robinson fuel, an ORIGEN* run was made to estimate the isotopic composition of the fuel. The results of the laboratory work and the computer run, shown in Table 4-1, were similar. Once the relative amounts of the actinides in the fuel were known, the absolute amount of one actinide present could be measured and the amounts of others calculated. According to a memo issued by

* ORIGEN is the Oak Ridge Isotope Generation Program, a nuclear fuel depletion code. 
TABLE 4-1. LABORATORY ANALYSIS AND ORIGEN

ESTIMATE OF ACTINIDE COMPOSITION

OF H.B. ROBINSON FUEL

(Cooled 6.5 Years)

\begin{tabular}{lcc}
\hline \hline $\begin{array}{c}\text { Element or } \\
\text { Isotope }\end{array}$ & $\begin{array}{c}\text { Laboratory Analysis } \\
\text { (in atom percent) }\end{array}$ & $\begin{array}{c}\text { ORIGEN Estimate } \\
\text { (in atom percent) }\end{array}$ \\
\hline Uranium & 100.000 & 100.000 \\
U-234 & 0.014 & 0.012 \\
U-235 & 0.578 & 0.576 \\
U-236 & 0.354 & 0.387 \\
U-238 & 99.054 & 99.025 \\
& & \\
Plutonium & 100.000 & 100.000 \\
Pu-238 & 1.784 & 1.862 \\
Pu-239 & 53.627 & 58.990 \\
Pu-240 & 27.546 & 25.331 \\
Pu-247 & 10.292 & 9.080 \\
Pu-242 & 6.751 & 4.737 \\
& & $5.543 \times 10^{-3}$ \\
Pu-239/U-238 & $4.973 \times 10^{-3}$ & $6.45 \times 10^{-3}$ \\
Cm-244/Pu-239 & $5.36 \times 10^{-3}$ & $6.1 \times 10^{-2}$ \\
Am-241/Pu-239 & $7.78 \times 10^{-2}$ & \\
\hline \hline
\end{tabular}


Catherine Mattsen (3), the five most hazardous actinides in fuel that has been cooled 5 years are Pu-238, -239 , and -240 , Am-241, and Cm-244 (see Table 4-2). All of these have relatively short half lives and are easy to detect. Therefore, the amounts of these five isotopes present were measured, and the results were used to calculate the total amount of spent fuel.

The procedure described below was used for each sample (cassette filter, cascade impactor slide, and debosition plate) collected. The filter, slide, or plate was put into nitric acid and heated until the fuel was dissolved. A portion of the solution was withdrawn and dried on a planchette. The planchette was then placed in an alpha detector for 2000 to 8000 seconds, depending upon the level of activity.

It was necessary to dissolve the samples for two reasons. First, a vacuum was pulled on the sample in the alpha detector. If the sampling devices were put directly into the detector, loose fuel particles would move around inside the chamber, contaminating the equipment. Second, spent fuel samples on the collection devices were thick enough to cause self-shielding of the alpha radiation. Dissolving the sample and drying a small amount of solution on a planchette solved both problems.

Figure 4-1 is a typical alpha spectrum of a spent fuel sample. It has three distinct peaks. The first peak contains counts from both Pu-239 and Pu-240; the second peak includes Pu-238 and Am-241; and the last peak is generated by $\mathrm{Cm}-244$. Ideally, each isotope should produce a separate peak, but the alpha energies of Pu-239 and -240 and of Pu-238 and Am-241 are nearly the same and could not be resolved with our detector.

It was, however, possible to determine what fraction of each peak was contributed by each isotope. Because both isotopes in the first peak were plutonium, they had the same physical and chemical characteristics. As a result, their relative concentrations in the sample should be the same as their relative concentrations in the fuel; that is, if the ratio of $\mathrm{Pu}-239$ to $\mathrm{Pu}-240$ in spent fuel is, for example, 4 , it should also be 4 in the sample. This ratio and the half lives of the isotopes were used to determine the fraction of counts in each peak contributed by each isotope. 
TABLE 4-2. PERCENT OF LATENT CANCER FATALITIES CAUSED BY SELECTED NUCLIDES

\begin{tabular}{lccc}
\hline Nuclide & $\begin{array}{c}\text { Type of } \\
\text { Radiation }\end{array}$ & $\begin{array}{c}\text { Energy } \\
\text { (MeV) }\end{array}$ & $\begin{array}{c}\text { Cumulative } \% \\
\text { of Fatalities }\end{array}$ \\
\hline Pu-238 & $\alpha$ & 5.4992 & 45.7 \\
Am-241 & $\alpha$ & 5.4857 & 65.1 \\
Cm-244 & $\alpha$ & 5.8050 & 82.9 \\
Pu-240 & $\alpha$ & 5.1683 & 89.7 \\
Pu-239 & $\alpha$ & 5.1550 & 95.3 \\
Pu-241 & $B$ & 0.0208 & 97.2 \\
Sr-90 & $B$ & 0.546 & 98.2 \\
Ru-106 & $\gamma$ & 0.512 .0 .622 & 99.1 \\
Ce-144 & $\gamma$ & 0.134 & 99.6 \\
Cs-137 & $\gamma$ & 0.662 & 99.8 \\
\hline
\end{tabular}

Note: Percentages from Catherine Mattsen's calculations. (3) 


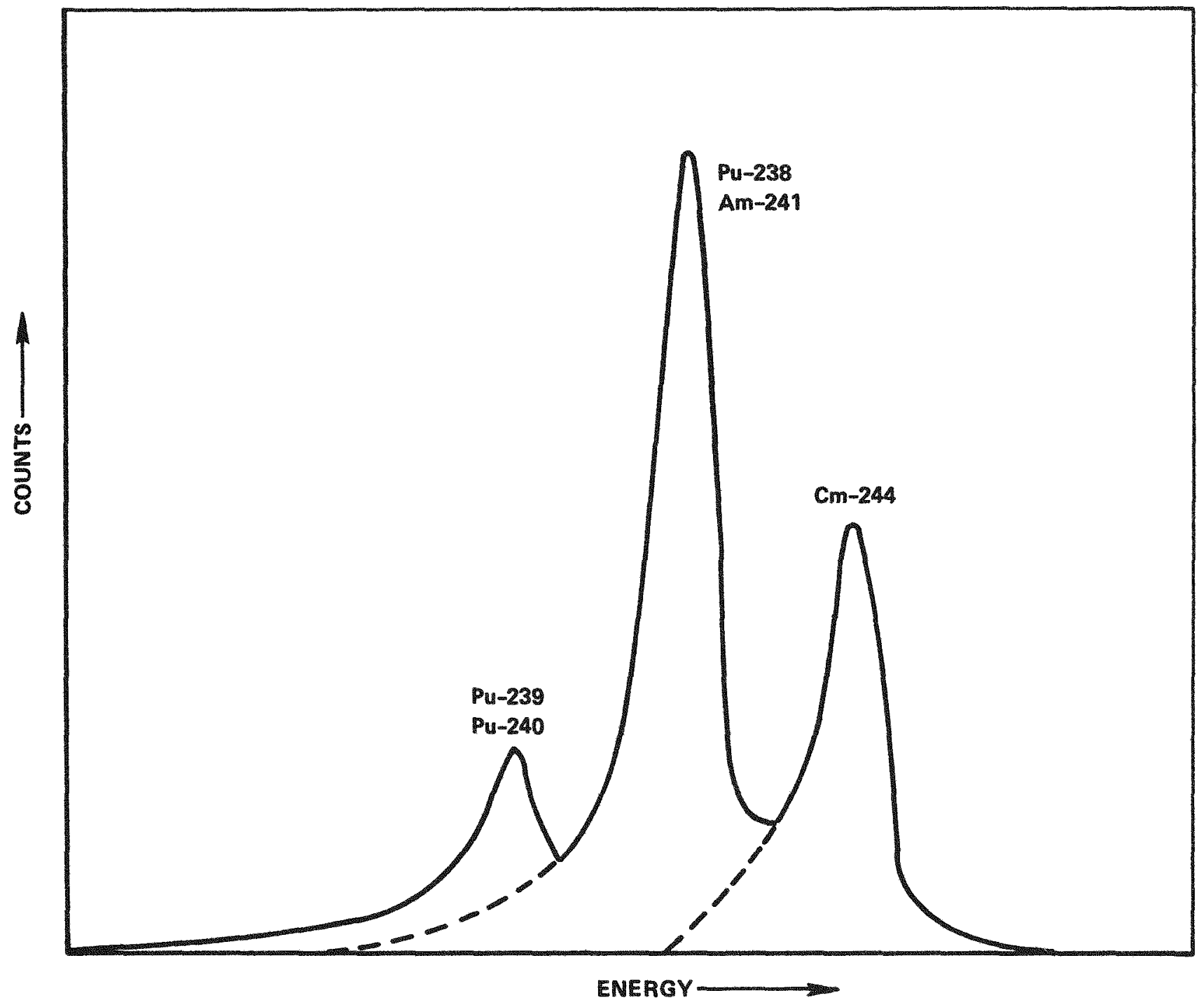

FIGURE 4-1. TYPICAL ALPHA SPECTRUM OF A SAMPLE 
Before the amount of each isotope present could be calculated accurately, it was necessary to know the true area (number of counts) under each peak. Generally, when the area under a peak is needed, the highest point is identified and then at some point to the left and some point to the right of the highest one, a vertical line is drawn to the axis. The area bounded by the curve, the axis, and the two vertical lines is the area under the peak. That area is then corrected for background. In an alpha spectrum, areas under peaks cannot be calculated the same way. Figure 4-1 shows an obvious tail to the left of the first peak. It occurred because many of the alphas emitted from the plutonium collided with atoms before reaching the detector. Consequently, they arrived at the detector with reduced energy. Alphas from other isotopes also arrive with reduced energy, so the other peaks have tails, too. Fortunately, the size and shape of those tails is fairly predictable, and it was possible to draw them in (dotted lines on Figure 4-1). In all succeeding calculations, the area under a peak included the area of its associated tail.

Using the number of counts in the first peak and the known ratio of Pu-239 to Pu-240, the amount of Pu-239 present was determined. Using the third peak, the amount of $\mathrm{Cm}-244$ was calculated. The ratio of $\mathrm{Cm}-244$ to Pu-239 was then computed. This ratio had been determined in the laboratory analys is as well. The laboratory and calculated values were almost identical. A small adjustment in the drawing of the tail (an adjustment about the thickness of a pencil point) made the two ratios exactly the same.

Next, it was assumed that Pu-238 and Am-241, having similar properties, would appear in the samples and in spent fuel in the same relative amounts. The amount of Am-241 in the sample was determined and the ratio of Am-241/Pu-239 calculated. Again, this ratio was nearly identical to the one determined by laboratory analysis.

All calculations up to this point showed that the relative concentrations of actinides in the samples were identical to those in the fuel. Thus, the U-238/PU-239 ratio established by the laboratory analys is was assumed to be correct for the samples and was used to determine the amount of uranium on each sampling device. 


\section{Disproportionation of Fission Products}

A second question that needed to be answered was whether disproportionation occurred, that is whether some nuclides were released from the fuel preferentially. Because some fission products tend to migrate to grain boundaries and because their vaporization temperatures are muchlower than that of $\mathrm{UO}_{2}$, there was some concern they might disproportionate when spent fuel was attacked with an energy intensive device. Four fission products ( $\mathrm{S} r-90, \mathrm{Cs}-137, \mathrm{Ce}-144$, and Ru-106) have been listed among the ten most hazardous isotopes in 5-year cooled fuel (see Table 4-2). If concentrations of those isotopes in the source term were orders of magnitude greater than their concentrations in spent fuel, they might present a greater health hazard than anticipated. Thus, an attempt was made to determine whether or not disproportionation occurred.

One of the four most hazardous fission products, $5 r-90$, is a beta emitter and very difficult to detect. It was not included in the analysis. Cesium-137, Ce-144, and Ru-106 are gamma emitters and could be analyzed. Cesium-134 and Eu-154 appeared in the gamma spectrum as well. Since they could be helpful in the analys is and adding them was a very minor expense, they were included.

A brief description of the method used to check for disproportionation is presented in the following paragraphs. Cascade impactor slides were the only sampling devices used for the disproportionation analysis. These slides were chosen because each one collected particles of a specific size. Since the disproportionation analys is was a determination of isotopic concentrations for various particle sizes, the impactor slides were the obvious sampling devices to use.

A gamma spectrum was generated for each impactor slide after it was removed from the sampling system. From the gamma spectrum the number of disintegrations per second (dps) for each isotope of interest was calculated. Then the fuel on the slide was dissolved and an alpha count was done, as described in the first part of this chapter. Using the alpha spectrum, the amount of uranium on the slide was calculated. Finally, the ratio of dps to micrograms of uranium was calculated for each isotope of interest and 
each impactor slide. These ratios have no physical meaning, and their absolute values were not of interest. The important observation to make was whether the ratio increased, decreased, or remained the same as particle size changed. If the ratio of disintegrations per second to micrograms of uranium increases substantially as particle size decreases, disproportionation has occurred. Results of the analysis for disproportionation, along with other results, are presented in the next chapter. 


\section{CHAPTER 5}

\section{RESULTS}

In order to characterize the source term resulting from the direct violation of a spent fuel shipping cask, data were analyzed to determine: (1) the mass and spatial distribution of the material released; (2) the size distribution of that material; and (3) its isotopic composition. The mass of material released and its particle size distribution were used to determine the respirable fraction of the released material. Information on the isotopic composition was used to determine whether the concentrations of some nuclides were greater in the spent fuel released from the cask than in the fuel remaining in the pins.

Table 5-1 presents information on each of the eight hot tests. The last column is of particular interest since it shows the total amount of fuel released from the cask during each test. The entries in Table 5-1 indicate that, as expected, more fuel was released from the half casks than from the full casks, and even more escaped from the no cask configuration. Furthermore, there was reasonably good agreement among the repeated shots with each type of cask. This agreement is most easily seen by using the "Fuel Disrupted" column and the "Out of Cask" column to calculate the percentage of disrupted fuel released from the cask. In Hot Shots 1,2, 7, and 8, a full cask, that is a sealed box with both a front and back wall, was used. The percentage of disrupted fuel released from the cask was $28,21,30$, and 29 percent for Shots $1,2,7$, and 8 , respectively. In Shots 3 and 4 , the backs of the casks were removed; 39 and 47 percent of the disrupted fue 1 was released during those two shots. No cask was used in Shots 5 and 6 , but a tray was placed beneath the pins, and the material that fell onto that tray was said to "remain in the cask". In These tests, 55 and 76 percent of the disrupted fuel was found outside of the cask. These two numbers are quite dissimilar. There is, however, a reason for the apparent disagreement. While the fuel pins from Shot 5 were being removed remotely from the experimental system, they were inadvertently bumped, causing more fuel to fall onto the tray beneath them. There was no way to determine how 
TABLE 5-1. HOT TEST MASS BALANCE DATA

\begin{tabular}{|c|c|c|c|c|c|c|}
\hline Experiment & $\begin{array}{l}\text { Shot } \\
\text { Date }\end{array}$ & $\begin{array}{l}\text { Cask } \\
\text { Type }\end{array}$ & $\begin{array}{l}\text { Total Pin } \\
\text { Weight, }(a) \\
g\end{array}$ & $\begin{array}{c}\text { Fuel } \\
\text { Disrupted, } \\
g\end{array}$ & $\begin{array}{c}\text { Fuel } \\
\text { In Cask, } \\
9\end{array}$ & $\begin{array}{c}\text { Fuel } \\
\text { Out of } \\
\text { Cask. } \\
g\end{array}$ \\
\hline HST & $4-20-81$ & Ful1 & 637.0 & 115.1 & 82.5 & 32.6 \\
\hline HS2 & $4-29-81$ & Ful1 & 645.0 & 81.3 & 64.5 & 16.9 \\
\hline HS3 & $5-7-81$ & $\mathrm{Half}$ & 639.2 & 136.5 & 83.5 & 53.0 \\
\hline HS4 & $5-28-81$ & Half & 644.5 & 121.9 & 64.3 & 57.6 \\
\hline HS5 & $6-5-81$ & No & 635.8 & 242.9 & $109.8^{(b)}$ & 133.1 \\
\hline HS6 & $6-15-81$ & No & 632.6 & 129.9 & $30.6^{(b)}$ & 99.3 \\
\hline HS7 & $6-9-82$ & Ful1 & 659.6 & 117.8 & 82.7 & 35.1 \\
\hline HS8 & $6-14-82$ & Fu11 & 655.7 & 131.0 & 93.2 & 37.7 \\
\hline
\end{tabular}

(a) Weight of fuel, cladding and steel plugs.

(b) In tray beneath pins. 
much fuel had been removed from the pins by the jet and how much fell out during subsequent handling. As a result, the reported amount of "fuel disrupted" is too high and the calculated percentage of fuel "out of cask" is unrealistically low.

There were relatively complete data for Shots 1, 2, 7, and 8 , which deserve the most attention since they employed full casks and were the most realistic. Perhaps the most important observation to make regarding the data for these shots is that nearly all of the material released from the cask is deposited on the chamber floor, walls and ceiling. If it is assumed that the reference jet does not penetrate both walls of the full scale cask, * then the deposition witnessed in the sampling chamber would occur inside the full scale cask. Since the deposition surfaces in a full scale cask (fuel pins, cask walls, support structures, etc.) would have a larger area and be closer to the jet's path than the chamber surfaces, deposition in a full scale situation would be more complete. Therefore, it is reasonable to take the initial airborne concentrations to be conservative estimates of release in a full scale situation.

The amounts of material deposited in various locations are given in Table 5-2. Figure 5-1 illustrates the positions of the deposition plates on which the deposited amounts were measured. In the Experiments HSI and HS2, the deposition plates were $47-\mathrm{mm}$ diameter stainless steel disks $117.35 \mathrm{~cm}^{2}$ area). In Experiments HS7 and HS8 the plates were $2.5 \times 7.5 \mathrm{-cm}$ stainless steel sheets $\left(18.75 \mathrm{~cm}^{2}\right.$ area) which had been coated with a thin film of glycerol to make the surface more adhesive for the depositing particles. (Plate number 11 was one-half width or $1.3 \times 7.5 \mathrm{~cm}\left(9.75 \mathrm{~cm}^{2}\right.$ area) to allow its positioning in the restricted space available near the jet inlet point.)

The data given in Table 5-2 indicate a considerable nonuniformity in deposited amount within the chamber. The locations near the jet entrance into and exit from the simulated cask show higher deposited amounts than other locations but vary somewhat with experiment. For example, deposited materials on both the floor and ceiling near the jet exit point from the cask are orders of magnitude higher than other surfaces in Experiment HS7.

* Private communication with R. P. Sandoval. 
TABLE 5-2. AMOUNTS OF URANIUM ON DEPOSITION PLATES

\begin{tabular}{ccccc}
\hline \hline $\begin{array}{c}\text { Deposition } \\
\text { Plate }\end{array}$ & \multicolumn{4}{c}{ Deposited MaSS, $\mu \mathrm{g}$} \\
\cline { 2 - 5 } 1 & HST & HS2 & HS7 & HS8 \\
\hline 2 & 179.8 & 170.0 & 210. & 3855. \\
3 & -- & 580.7 & 418. & 1548. \\
4 & -- & -- & -- & -- \\
5 & 17.7 & 43.3 & 278. & 1154. \\
6 & -- & 176.6 & 59. & 1073. \\
7 & 20.1 & 538.2 & -- & -- \\
8 & 26.3 & 242.4 & 102. & 1830. \\
9 & -- & -- & $38,058$. & -- \\
10 & -- & -- & $11,027$. & -- \\
11 & -- & -- & 452. & 295. \\
12 & -- & -- & 742. & -- \\
13 & -- & -- & 653. & 2100. \\
14 & -- & -- & 180. & 3949. \\
15 & 1941. & 1293. & $16,177$. & 2505. \\
\hline \hline
\end{tabular}

Note: Dashes in the above table indicate that no data were available. 


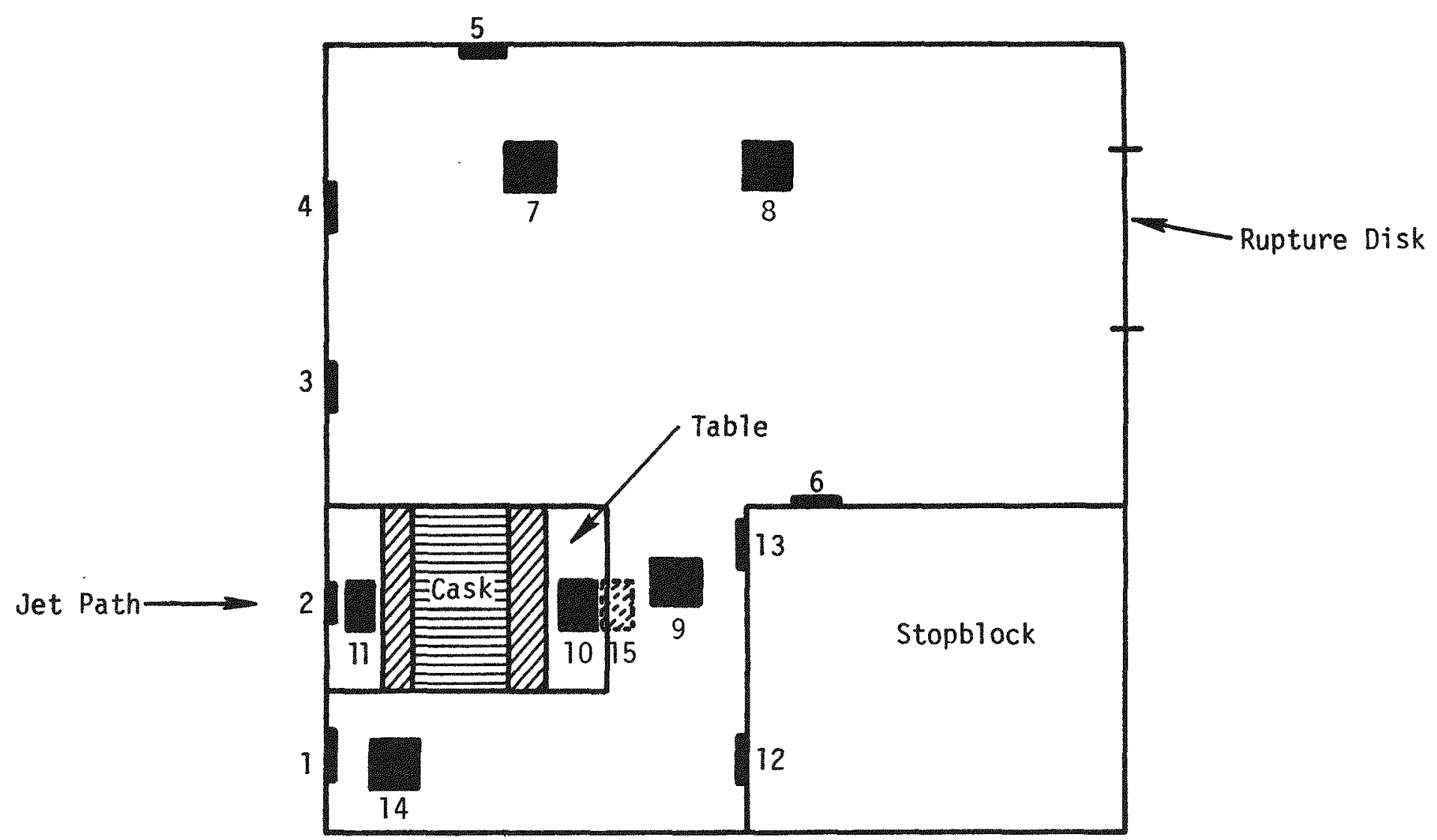

Notes: Plates $1,2,3,4,5,6,12$, and 13 are on the wal1s. Plate 2 is above the jet entrance hole.

Plates $7,8,9$, and 14 are on the floor.

Plates 10 and 11 are on the table that supports the cask (about $7 "$ above the floor).

plate 15 is on the ceiling above the indicated spot.

FIGURE 5-1. LOCATIONS OF DEPOSITION PLATES ON SURFACES WITHIN THE TEST CHAMBER 
In all cases, rough estimates indicate that almost all of the material leaving the cask is deposited on internal chamber surfaces. The variations in surface deposit with location are believed to be random fluctuations in the behavior of the jet penetration and the accompanying gas flow patterns.

Since the distances between deposition surfaces in the chamber are greater than similar distances within a full scale cask, it follows that inertial deposition of particulate material will occur less efficiently within the test chamber than within a full scale cask. Therefore, airborne mass concentrations in the chamber are greater than would be expected at full scale. This conclusion can be substantiated further by examining the timedependent nature of the airborne concentration as well as measured airborne particle size distributions.

Figure 5-2 shows the airborne concentration with time in the first 10 minutes of the experiment. Data were collected for two sampler locations in each of the four hot experiments. The total data set is presented in Table 5-3. From the total data set, the higher concentration values were selected because, particularly in the HSI and HS2 experiments, the sampling was believed to be partially ineffective. The concentration decrease with time shown in Figure 5-2 results from sedimentation onto the chamber floor plus dilution resulting from the sampling.

Extrapolating back to zero time (initial concentration) gives the airborne concentration released to the chamber air. This airborne mass is comprised of the material released from the fuel but not immediately deposited on the walls by impaction. It shows that for the four hot experiments, the initial concentration ranged from about 50 to $500 \mathrm{\mu g} / 1$ liter. Most of the data indicate initial concentration levels in the range from about 50 to 200 $\mu \mathrm{g} /$ liter with the higher values being collected from just above the point of jet exit from the cask.

The time-dependent airborne concentrations for Experiment HS7 are shown in Figure 5-3 for times out to 85 minutes. Predictions of this concentration behavior were made with the HAARM-3 code and the results are also shown in Figure 5-3 for two sets of assumptions. The upper computer prediction uses an initial aerodynamic particle size of $5 \mu \mathrm{m}$ as found experimentally by impactor measurements. The impactor results are shown in Figure 5-4. 


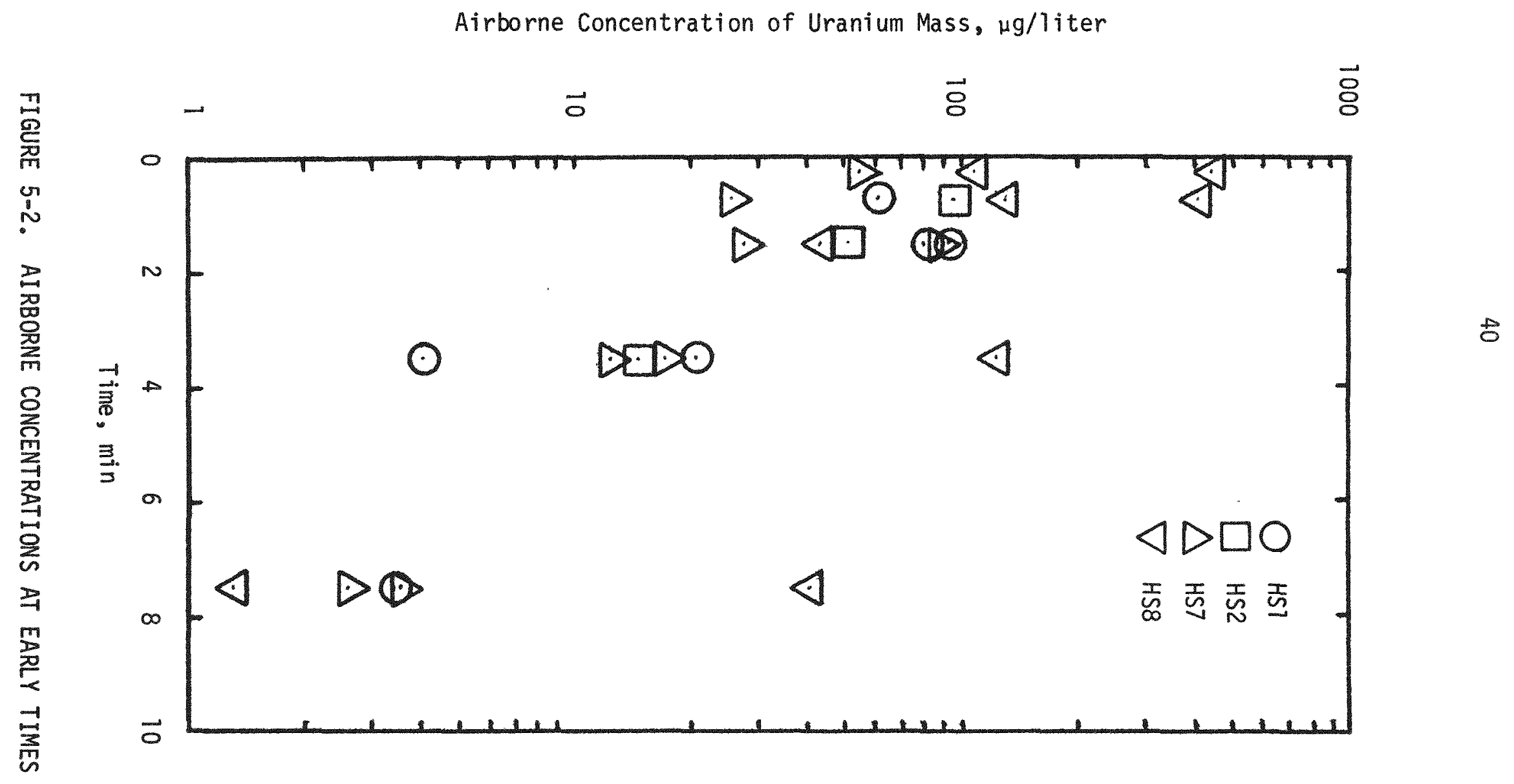


TABLE 5-3. AIRBORNE URANIUM MASS CONCENTRATIONS

\begin{tabular}{|c|c|c|c|c|c|c|c|}
\hline Experiment & Run & Sample & & $\begin{array}{c}\text { Time } \\
\text { Interval, } \\
\text { min }\end{array}$ & $\begin{array}{c}\text { Sampling } \\
\text { Flow } \\
\text { Rate, } \\
\mathrm{l} / \mathrm{min}\end{array}$ & $\begin{array}{c}\text { U Mass } \\
\text { Collected, } \\
\mu \mathrm{g}\end{array}$ & $\begin{array}{c}\text { Airborne } \\
\text { Concentration, } \\
\mu \mathrm{g} / \mathrm{l}\end{array}$ \\
\hline \multirow[t]{3}{*}{ Hot Shot 1} & 1 & $\begin{array}{l}\text { Cassette } \\
\text { Fil ter: }\end{array}$ & $\begin{array}{l}1 \\
1 \\
2 \\
3 \\
4 \\
5\end{array}$ & $\begin{array}{l}0-0.5 \\
0.5-1.0 \\
1.0-2.0 \\
2.0-5.0 \\
5.0=10.0\end{array}$ & $\begin{array}{c}10^{(\mathrm{a})} \\
10 \\
10 \\
10 \\
10\end{array}$ & $\begin{array}{r}0 \\
19.8 \\
938.3 \\
612.1 \\
9.1\end{array}$ & $\begin{array}{l}-- \\
4.00 \\
93.8 \\
20.4 \\
0.18\end{array}$ \\
\hline & 1 & $\begin{array}{l}\text { Cassette } \\
\text { Filter: }\end{array}$ & $\begin{array}{l}2 \\
1 \\
2 \\
3 \\
4 \\
5\end{array}$ & $\begin{array}{c}0-0.5 \\
0.5-1.0 \\
1.0-2.0 \\
2.0-5.0 \\
5.0-10.0\end{array}$ & $\begin{array}{l}10 \\
10 \\
10 \\
10 \\
10\end{array}$ & $\begin{array}{c}0 \\
301.0 \\
798.2 \\
120.2 \\
169.4\end{array}$ & $\begin{array}{l}-- \\
60.2 \\
79.8 \\
4.01 \\
3.39\end{array}$ \\
\hline & 2 & $\begin{array}{l}\text { Cassette } \\
\text { Filter: }\end{array}$ & $\begin{array}{l}1 \\
1 \\
2 \\
3 \\
4 \\
5\end{array}$ & $\begin{array}{l}60-65 \\
65-70 \\
70-75 \\
75-80 \\
80-85\end{array}$ & $\begin{array}{l}10 \\
10 \\
10 \\
10 \\
10\end{array}$ & $\begin{array}{l}3.761 \\
0.094 \\
0.479 \\
0.057 \\
-\end{array}$ & $\begin{array}{l}0.075 \\
0.0019 \\
0.0096 \\
0.0011 \\
-\end{array}$ \\
\hline Hot Shot 2 & 1 & $\begin{array}{l}\text { Cassette } \\
\text { Filter: }\end{array}$ & $\begin{array}{l}1 \\
1 \\
2 \\
3 \\
4 \\
5\end{array}$ & $\begin{array}{c}0-0.5 \\
0.5-1.0 \\
1.0-2.0 \\
2.0-5.0 \\
5.0-10.0\end{array}$ & $\begin{array}{l}10 \\
10 \\
10 \\
10 \\
10\end{array}$ & $\begin{array}{r}9.4 \\
3.6 \\
506.0 \\
441.3 \\
16.8\end{array}$ & $\begin{array}{c}1.88 \\
0.72 \\
50.6 \\
14.7 \\
0.34\end{array}$ \\
\hline
\end{tabular}


TABLE 5-3. (Continued)

\begin{tabular}{|c|c|c|c|c|c|c|c|}
\hline Experiment & Run & Sample & & $\begin{array}{l}\text { T'ime } \\
\text { Interval, } \\
\text { min }\end{array}$ & $\begin{array}{c}\text { Sampling } \\
\text { Flow } \\
\text { Rate, } \\
\ell / \text { min }\end{array}$ & $\begin{array}{c}\text { U Mass } \\
\text { Collected, } \\
\mu \mathrm{g}\end{array}$ & $\begin{array}{c}\text { Airborne } \\
\text { Concentration, } \\
\mu g / \ell\end{array}$ \\
\hline \multirow[t]{2}{*}{ Hot Shot 2} & 1 & $\begin{array}{l}\text { Cassette } \\
\text { Filter: }\end{array}$ & $\begin{array}{l}2 \\
1 \\
2 \\
3 \\
4 \\
5\end{array}$ & $\begin{array}{c}0-0.5 \\
0.5-1.0 \\
1.0-2.0 \\
2.0-5.0 \\
5.0-10.0\end{array}$ & $\begin{array}{l}10 \\
10 \\
10 \\
10 \\
10\end{array}$ & $\begin{array}{r}2.4 \\
477.5 \\
0.3 \\
6.5 \\
2.8\end{array}$ & $\begin{array}{l}0.48 \\
95.5 \\
0.03 \\
0.22 \\
0.056\end{array}$ \\
\hline & 2 & $\begin{array}{l}\text { Cassette } \\
\text { Filter: }\end{array}$ & $\begin{array}{l}1 \\
1 \\
2 \\
3 \\
4 \\
5\end{array}$ & $\begin{array}{l}60-65 \\
65-70 \\
70-75 \\
75-80 \\
80-85\end{array}$ & $\begin{array}{l}10 \\
10 \\
10 \\
10 \\
10\end{array}$ & $\begin{array}{r}12.5 \\
0.7 \\
10.7 \\
16.6 \\
23.8\end{array}$ & $\begin{array}{l}0.25 \\
0.0071 \\
0.21 \\
0.33 \\
0.48\end{array}$ \\
\hline \multirow[t]{3}{*}{ Hot Shot 7} & 1 & $\begin{array}{l}\text { Cassette } \\
\text { Filter: }\end{array}$ & $\begin{array}{l}1 \\
1 \\
2 \\
3 \\
4 \\
5\end{array}$ & $\begin{array}{c}0-0.5 \\
0.5-1.0 \\
1.0-2.0 \\
2.0-5.0 \\
5.0-10.0\end{array}$ & $\begin{array}{l}12.9 \\
13.6 \\
14.0 \\
13.5 \\
13.5\end{array}$ & $\begin{array}{l}351.1 \\
172.9 \\
388.7 \\
496.5 \\
239.9\end{array}$ & $\begin{array}{r}54.5 \\
25.4 \\
27.8 \\
12.3 \\
3.6\end{array}$ \\
\hline & 1 & $\begin{array}{l}\text { Cassette } \\
\text { Filter: }\end{array}$ & $\begin{array}{l}2 \\
1 \\
2 \\
3 \\
4 \\
5\end{array}$ & $\begin{array}{c}0-0.5 \\
0.5-1.0 \\
1.0-2.0 \\
2.0-5.0 \\
5.0-10.0\end{array}$ & $\begin{array}{l}14.1 \\
14.1 \\
14.3 \\
13.9 \\
13.7\end{array}$ & $\begin{array}{c}435.2 \\
-- \\
1214.0 \\
723.3 \\
176.7\end{array}$ & $\begin{array}{r}61.7 \\
-- \\
84.9 \\
17.3 \\
2.6\end{array}$ \\
\hline & 2 & $\begin{array}{l}\text { Cassette } \\
\text { Filter: }\end{array}$ & $\begin{array}{l}1 \\
1 \\
2 \\
3 \\
4 \\
5\end{array}$ & $\begin{array}{l}60-65 \\
65=70 \\
70-75 \\
75=80 \\
80-85\end{array}$ & $\begin{array}{l}14.1 \\
14.2 \\
13.8 \\
14.0 \\
13.9\end{array}$ & $\begin{array}{r}140.6 \\
50.9 \\
88.2 \\
38.9 \\
29.1\end{array}$ & $\begin{array}{l}1.99 \\
0.72 \\
1.28 \\
0.56 \\
0.42\end{array}$ \\
\hline
\end{tabular}


TABLE 5-3. (Continued)

\begin{tabular}{|c|c|c|c|c|c|c|c|}
\hline Experiment & Run & Sample & & $\begin{array}{l}\text { Time } \\
\text { Interval, } \\
\text { min }\end{array}$ & $\begin{array}{c}\text { Sampling } \\
\text { Flow } \\
\text { Rate, } \\
\text { l/min }\end{array}$ & $\begin{array}{c}\text { U Mass } \\
\text { Collected, } \\
\mu \mathrm{g}\end{array}$ & $\begin{array}{c}\text { Airborne } \\
\text { Concentration, } \\
\mu \mathrm{g} / \ell\end{array}$ \\
\hline \multirow[t]{6}{*}{ Hot Shot 7} & 2 & Cassette & 2 & & & & \\
\hline & & Filter: & 1 & $60-65$ & 14.0 & 119.2 & 1.70 \\
\hline & & & 2 & $65-70$ & 14.0 & 44.8 & 0.64 \\
\hline & & & 3 & $70-75$ & 14.1 & 32.9 & 0.47 \\
\hline & & & 4 & $75-80$ & 14.1 & 27.7 & 0.39 \\
\hline & & & 5 & $80-85$ & 11.4 & 23.9 & 0.42 \\
\hline \multirow[t]{12}{*}{ Hot Shot 8} & 1 & Cassette & 1 & & & & \\
\hline & & Fi1ter: & 1 & $0-0.5$ & 13.0 & 2905 & 447 \\
\hline & & & 2 & $0.5-1.0$ & 13.0 & 2674 & 411 \\
\hline & & & 3 & $1.0-2.0$ & 14.0 & 6 & - \\
\hline & & & 4 & $2.0-5.0$ & 13.5 & 4988 & 123 \\
\hline & & & 5 & $5.0-10.0$ & 13.5 & 2738 & 40.5 \\
\hline & 1 & Cassette & 2 & & & & \\
\hline & & Filter: & 1 & $0-0.5$ & 14.1 & 759 & 107.7 \\
\hline & & & 2 & $0.5-1.0$ & 14.1 & 916 & 129.9 \\
\hline & & & 3 & $1.0-2.0$ & 15.7 & 677 & 43.1 \\
\hline & & & 4 & $2.0-5.0$ & 13.8 & - & - \\
\hline & & & 5 & $5.0-10.0$ & 13.7 & 89 & 1.3 \\
\hline
\end{tabular}

(a) Flow rates for sample collections in Hot Shots 1 and 2 are approximated and based on prior calibration rather than measured at time of sampling. 


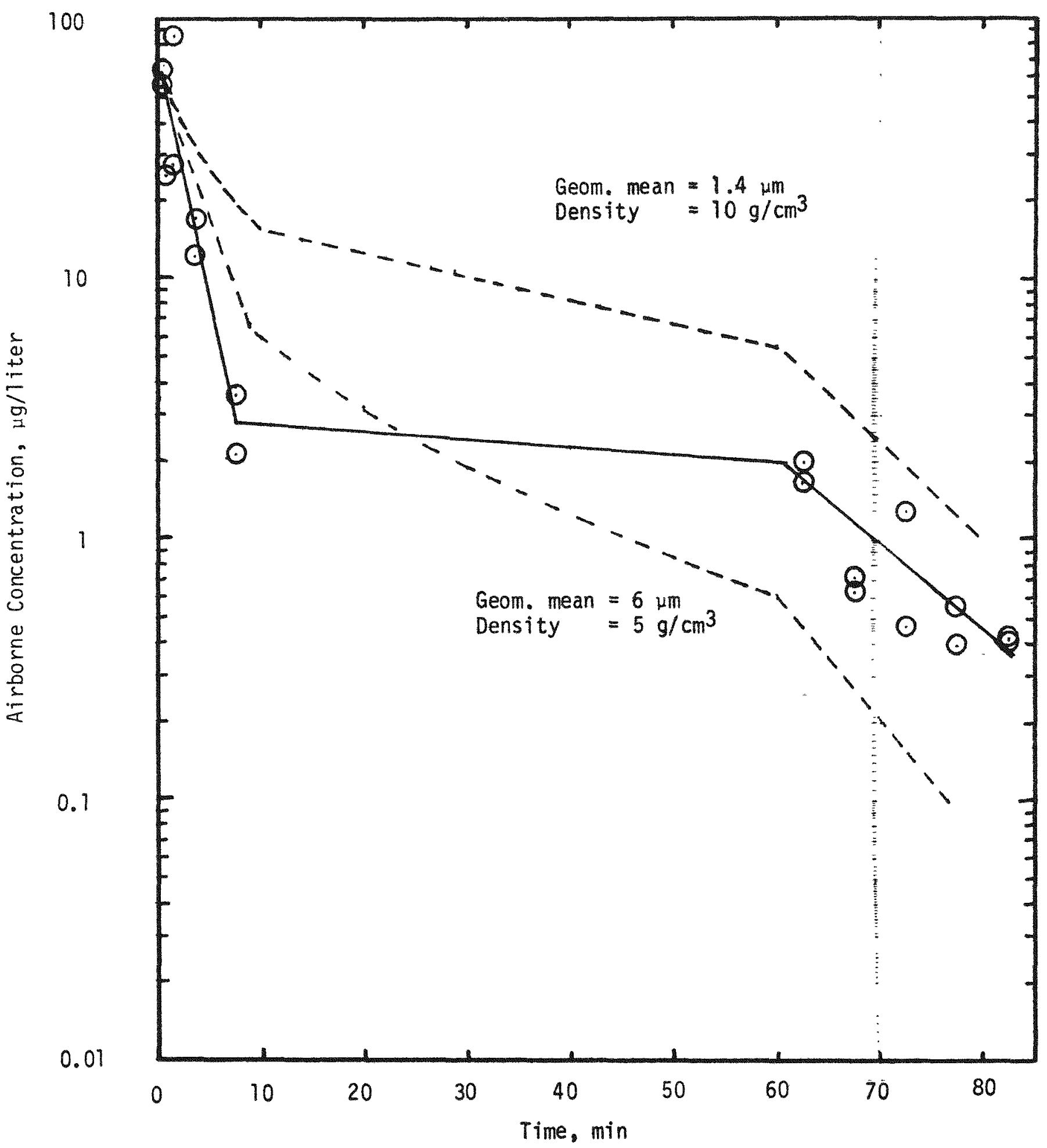

FIGURE 5-3. MEASURED AND PREDICTED AIRBORNE CONCENTRATIONS FOR HS7 


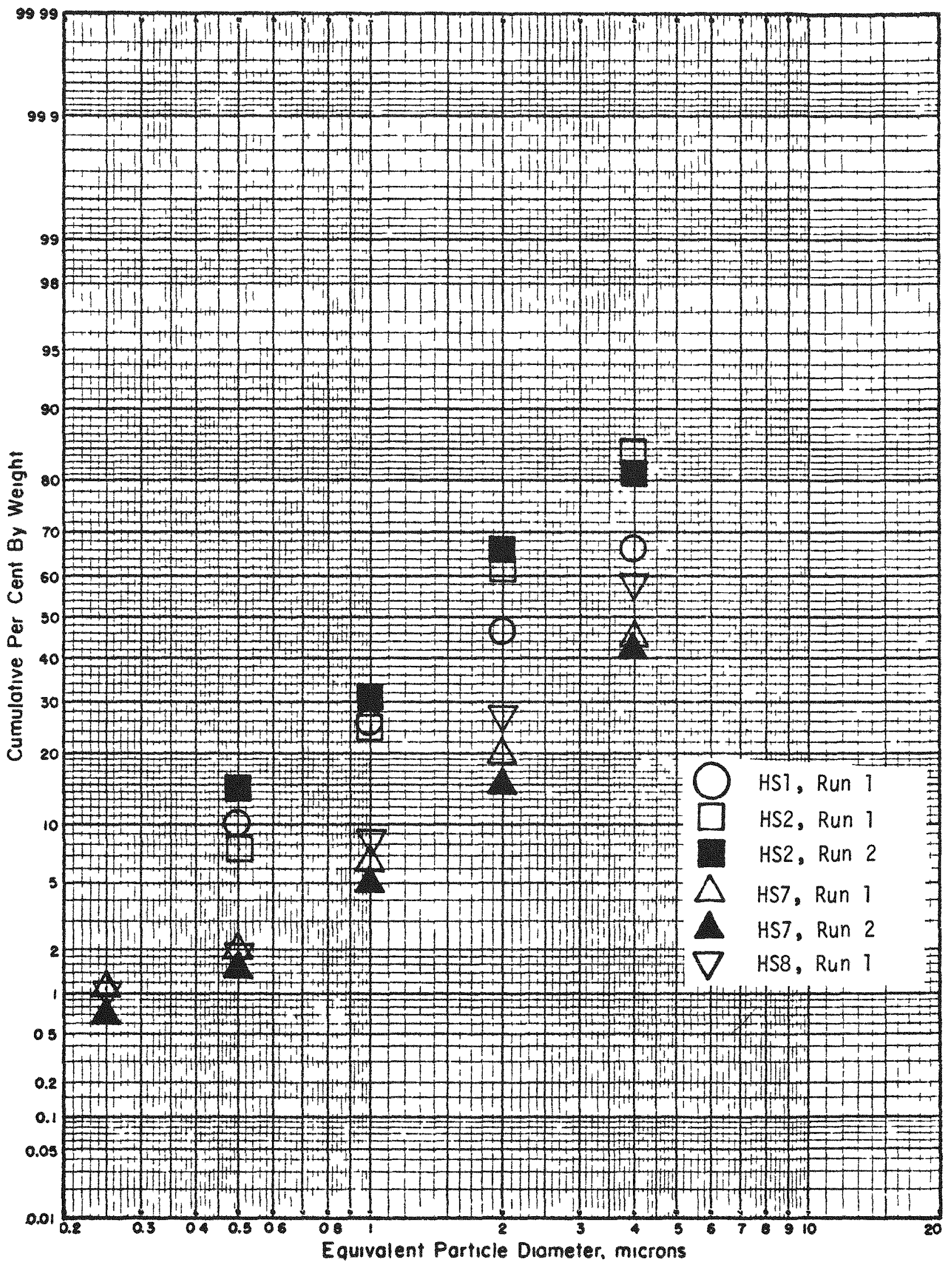

FIGURE 5-4. AIRBORNE PARTICLE SIZE DISTRIBUTIONS 
The lower curve assumes a much larger initial particle size for comparison. The intent of the computer predictions is to illustrate that the behavior of the airborne concentration with time is explained in terms of standard aerosol behavior. The early time reduction in concentration results from sedimentation and sampling flow dilution of the chamber. The concentration decline beyond one hour is almost completely the result of the sampling flow.

The slope of the airborne concentration curves near time zero indicate a significant fraction of large particles were settling out quite rapidly. The concave upward shape of the particle size distribution curves (especially for the better data from HS7 and HS8, Figure 5-4) indicate some truncation of the larger particles if there was originally a log normal distribution produced in the chamber. These observations coupled with the fact that near the jet, the surface concentrations tended to be much greater suggest a mechanism whereby large particles are almost instantaneously removed by impaction on surfaces and are rapidly removed thereafter by sedimentation. The size distributions integrated over the 10-minute sampling time show mean sizes of only about $4 \mu \mathrm{m}$, probably truncation on the larger-particle end. Therefore it follows that in a full-scale cask where distances between the jet and potential deposition surfaces are smaller, more inertial deposition wi1l occur than was observed in the test chamber. This means that respirable airborne amounts in the chamber provide a conservative estimate of released respirable material. As a further conservatism, it is recommended that the total release be assumed respirable even though only about 50 percent was found respirable in the measured size distributions. Therefore, it is recommended that the initial measured airborne concentrations be used to give a conservative value for released respirable mass.

Finally, the data were analyzed to determine whether or not disproportionation occurred. A brief description of the method used to investigate disproportionation was presented in Chapter 4 . Table 5-4 presents the results of the analyses for $\operatorname{Cs}-134$ and $\operatorname{cs}-137$ in shots 1 and 2 . The entries in the table are in units of disintegrations per second (of Cesium) divided by micrograms (or Uranium). Recall that the entries have no physical meaning but that it is important to observe how the values change as particle size changes. 
TABLE 5-4. RATIOS OF CESIUM TO URANIUM

FOR VARIOUS PARTICLE SIZES

\begin{tabular}{|c|c|c|c|c|}
\hline \multicolumn{3}{|c|}{ EXPERIMENT HST: } & \multirow{2}{*}{$\begin{array}{l}\text { Column } 2 \\
\text { Normalized } \\
\text { to Ratio } \\
\text { for }>4 \mathrm{um} \\
\end{array}$} & \multirow{2}{*}{$\begin{array}{l}\text { Column } 3 \\
\text { Normalizec } \\
\text { to Ratio } \\
\text { for }>4 \mathrm{~mm}\end{array}$} \\
\hline $\begin{array}{l}\text { Particle } \\
\text { Size (um) }\end{array}$ & $\begin{array}{c}\text { dps Cs-137/ } \\
\mu g U^{*}\end{array}$ & $\begin{array}{c}d p s c s-134 / \\
\mu g U^{\star \star}\end{array}$ & & \\
\hline$>4$ & 0.41 & 0.58 & 1.00 & 1.00 \\
\hline $2-4$ & 0.82 & 1.19 & 2.00 & 2.05 \\
\hline $1-2$ & 0.91 & 1.33 & 2.22 & 2.29 \\
\hline $1 / 2-7$ & 2.93 & 4.25 & 7.15 & 7.38 \\
\hline $1 / 4-7 / 2$ & 7.16 & 10.23 & 17.46 & 17.64 \\
\hline
\end{tabular}

EXPERIMENT HS2:

\begin{tabular}{crrrr}
\hline$>4$ & 0.23 & 0.32 & 1.00 & 1.00 \\
$2-4$ & 0.30 & 0.42 & 1.30 & 1.31 \\
$1-2$ & 0.45 & 0.63 & 1.96 & 1.97 \\
$1 / 2-1$ & 1.30 & 1.80 & 5.65 & 5.62 \\
$1 / 4-1 / 2$ & 3.83 & 5.32 & 16.65 & 16.62 \\
\hline
\end{tabular}

* Ratios have been multiplied by $10^{-5}$ to get values shown in the table.

** Ratios have been multiplied by $10^{-4}$. 
There appears to be a definite trend toward higher concentrations of fission products in smaller particies. Note that the values of the ratios of CS-134/U and CS-137/U are different because the isotopes are produced in different quantities during fission. However, in both cases, the ratio for particles of diameter $1 / 4-1 / 2 \mu \mathrm{m}$ is about 17 times as great as the ratio for particles greater than $4 \mu \mathrm{m}$. Because the two cesium isotopes have the same physical and chemical characteristics, it was expected that their change in concentration with particle size, which is caused by physical and chemical phenomena, should be the same.

Analysis of other isotopes for disproportionation did not yield conclusive results. Figure 5-5, a drawing of a typical gamma scan from an impactor slide, shows why. Cesium-137 is clearly the most abundant gamma emitter in the sample, followed by Cs-134. Not only is the Cs-137 peak the largest, but the Compton scatter from the Cs-137 creates a "background" (represented by the gently sloping line in Figure 5-5) that interferes with the other peaks. Because the peaks for other isotopes are very small and because the CS-137 backscatter interferes with them, it is generally not possible to measure them accurately.

However, in one shot (Shat 3), the cascade impactor collected sufficient material for analysis. Even though Cs-137 dominated the gamma spectrum, there were enough counts in the other peaks to produce reasonably accurate results. Table 5-5 shows the ratio of dps of each isotope studied to micrograms of uranium for various particle sizes. Table 5-6 was generated from Table 5-5 by normalizing each column to the first entry (the $\mathrm{dps} / \mathrm{\mu g} U$ ratio for particles greater than $4 \mu \mathrm{m}$ ). Thus, as one reads down the Cs-137/U column, for example, the second entry indicates that the concentration of $\mathrm{Cs}_{5}-137$ in particles of $2-4 \mu \mathrm{m}$ is 1.61 times greater than the concentration in particles greater than $4 \mu \mathrm{m}$. 


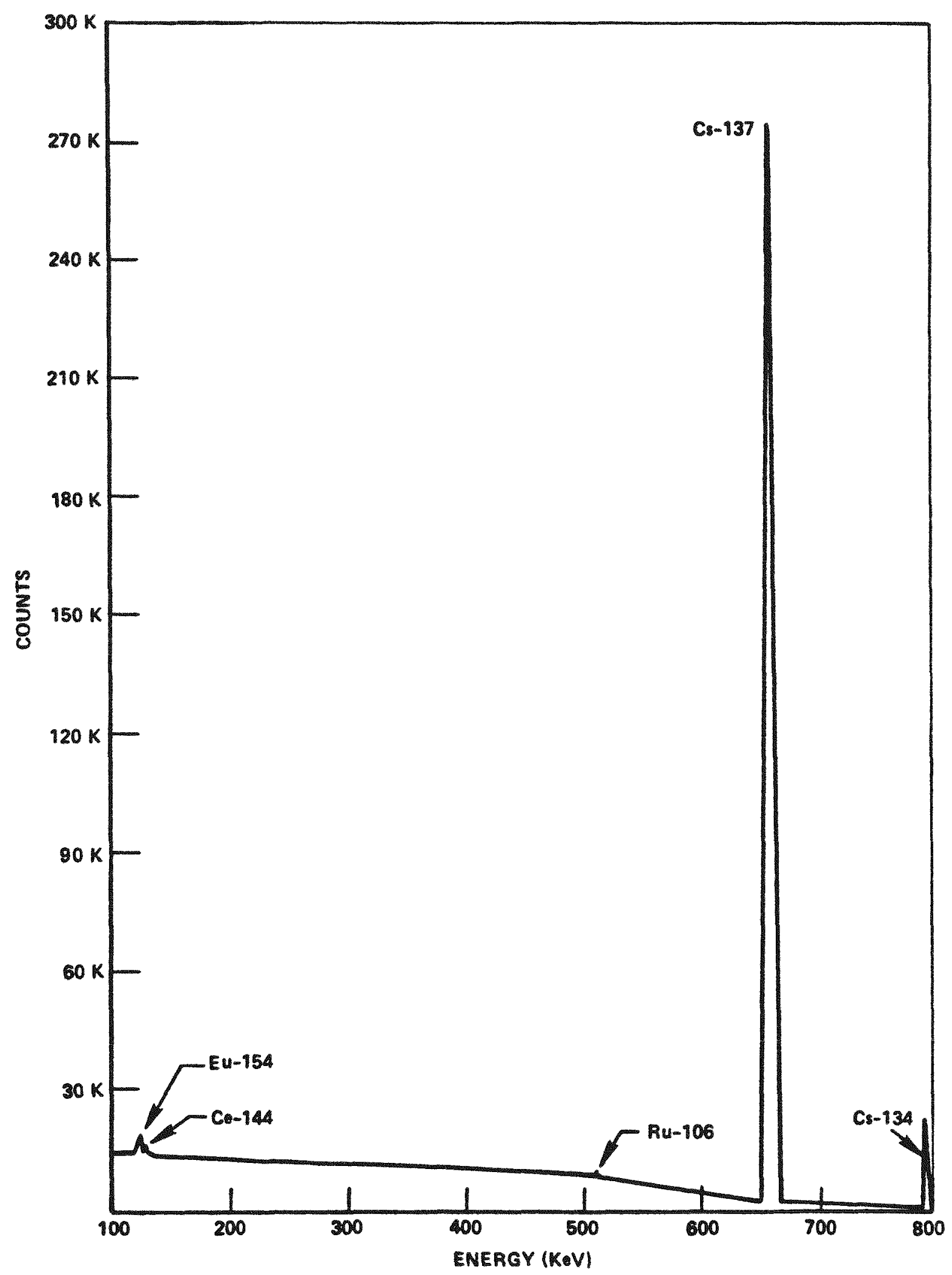

FIGURE 5-5. TYPICAL GAMMA SPECTRUM FROM SPENT FUEL SAMPLE 
TABLE 5-5. RATIOS OF FISSION PRODUCTS TO URANIUM FOR VARIOUS PARTICLE SIZES (EXPERIMENT 3)

\begin{tabular}{|c|c|c|c|c|c|}
\hline $\begin{array}{l}\text { Particle } \\
\text { size (um) }\end{array}$ & $\begin{array}{l}\text { dps Cs-137/ } \\
\mu g \cup(a) \\
\end{array}$ & $\begin{array}{l}\operatorname{dps} C s-134 / \\
\mu g \cup(b)\end{array}$ & $\begin{array}{l}\operatorname{dps}\{u-154 / \\
\mu g U^{(c)}\end{array}$ & $\begin{array}{l}\operatorname{dps} C \xi-{ }^{44 /} \\
\mu g u\end{array}$ & $\begin{array}{l}\text { dps Ru-106/ } \\
n g U^{(c)}\end{array}$ \\
\hline$>4$ & 0.36 & 0.45 & 0.18 & 0.77 & 0.36 \\
\hline $2-4$ & 0.58 & 0.72 & 0.21 & 0.35 & 0.39 \\
\hline $1-2$ & 0.98 & 1.29 & 0.22 & 1.52 & 0.64 \\
\hline $1 / 2-1$ & 2.75 & 3.49 & 0.34 & 1.93 & 1.18 \\
\hline $1 / 4-1 / 2$ & 3.78 & 4.83 & 0.28 & 3.33 & 1.83 \\
\hline
\end{tabular}

TABLE 5-6. RATIOS FROM TABLE 5-5 NORMALIZED TO THE FIRST RATIO IN EACH COLUMN

\begin{tabular}{cccccc}
\hline \hline $\begin{array}{l}\text { Particle } \\
\text { Size (jm) }\end{array}$ & Cs-137 & Cs-134 & Eu-154 & Ce-144 & Ru-106 \\
\hline$>4$ & 1.00 & 1.00 & 1.00 & 1.00 & 1.00 \\
$2-4$ & 1.61 & 1.60 & 1.17 & 0.45 & 1.08 \\
$1-2$ & 2.72 & 2.87 & 1.22 & 1.97 & 1.78 \\
$1 / 2-1$ & 7.64 & 7.76 & 1.89 & 2.51 & 3.28 \\
$1 / 4-1 / 2$ & 10.50 & 10.73 & 1.56 & 4.32 & 5.08 \\
& & & & & \\
\hline
\end{tabular}

(a) Ratios have been multiplied by $10^{-5}$ to get values shown in the table.

(b) Ratios have been multiplied by $10^{-4}$.

(c) Ratios have been multiplied by $10^{-3}$.

(d) Ratios have been multiplied by $10^{-2}$. 
Only one conclusion on disproportionation can be drawn with any certainty: cesium concentration increases as particle size decreases. There are data to suggest that europium's concentration does not vary with particle size and that ruthenium's and cerium's concentrations do increase as particle size decreases. However, their increases are not as great as cesium's.

The reason for studying disproportionation was to determine whether fission products would be released preferentially and be a greater health hazard than anticipated. Results of the analysis lead to the conclusion that even with the disproportionation, the effects of $\mathrm{Cs}-137$ are far less than those of any of the actinides. There are two primary reasons for that conclusion. First, only in the very fine particles (1/4$1 / 2 \mathrm{\mu m}$ ) is there evidence of strong disproportionation, and those fine particles represent a very small fraction of the mass of Cs-137 released. Second, even if the unrealistic worst case is assumed, and 17 times more cesium is released than expected, Cs accounts for only $3.4 \%$ latent fatalities - - fewer than any of the five actinides studied. 


\section{CHAPTER 6}

\section{SCALING ANALYSIS}

\section{Objective}

The objective of the scaling analysis described here was to predict the ratio of the radiological source term expected from the sub-scale precision shaped charge jet used in the experimental source term investigation to that expected from the reference basis threat, an $M-3$ shaped charge.

\section{Basic Premise for Scaling}

The complete radiological source term consists of the particle size distribution of all radioactive (irradiated $\mathrm{UO}_{2}$ ) mass released from the shipping cask or its sub-scaled counterpart. However, the most serious consequences of the radiological source term result from particles in the respirable size range, $\leq 3.5$ microns. Hence, in this analys is we focus on processes which are likely to produce large mass fractions of material in this size range.

High pressure shock compression has been most extensively studied under planar impact and shock wave conditions. Although these conditions are not satisfied for the overall jet penetration process, local regions of the curved shock fronts approximate these conditions. Under planar shock compression, the conditions may be characterized as one-dimensional strain, i.e., no dimensional changes occur except in the direction of shock propagation. Under these conditions, for a material with finite shear strength, the initial compression is resisted not only by the bulk modulus of compression but by the elastic shear modulus. As the magnitude of shock stress increases, the maximum shear stress the material can support elastically is exceeded and the material fails in shear. The shock pressure associated with this shear failure is called the Hugoniot Elastic Limit ${ }^{(4)}$ (HEL). The shear failure above the HEL in ductile materials simply introduces plastic deformation into the material. In brittle material such as $\mathrm{UO}_{2}$, the shear failure could cause the production of many fine particles after release of the pressure. 
The HEL includes a significant component of hydrostatic pressure as well as a component from the elastic distortion associated with onedimensional strain. It is possible to fracture a brittle material at stresses appreciably below the HEL but in this case the amount of very fine scale fracturing will be more limited.

For the purpose of this scaling analysis, we introduce the assumption that the amount of respirable fine particles produced by a jet impact is proportional to the volume of target fuel pin material shocked to pressures in excess of the HEL. In the subsequent analyses we attempt to assess these volumes for the two threats considered.

\section{Technical Discussion}

First, we present a comparison of some of the parameters of the reference basis and precision shaped charge as shown in Table 6-1. The reference basis threat is an Army Engineer demolition charge developed in the 1940's primarily for penetration of concrete structures such as paved highways. It is not a high precision device and significant variations in round to round performance on the order of 50 percent are to be expected. (5) The jet from this device has been partially characterized by recent work at Sandia under DOE funding.

Figure 6-1 shows a flash $X$-ray radiograph of the $M-3$ jet in flight at $\sim 1.75 \mathrm{~m}$ stand-off which may be near optimum for some applications. ${ }^{(6)}$ The jet is a stream of more or less equixial, irregular iron particles with significant spacing between the particles. The non-precision nature of the device leads to some irregular deviations from a straight line alignment of the particles in the jet as shown in other flash $X$-radiographs taken at Sandia National Laboratories. Note that the jet particle diameter is larger than the diameter of PWR fuel pin $(\sim 10 \mathrm{~mm})$. 
TABLE 6-1. COMPARISON OF REFERENCE THREAT TO PRECISION SHAPED CHARGE

\section{Design Features}

Liner

Cone Diameter, m

Cone Angle*, degrees

Material

\section{Explosive}

Fabrication Method

Composition

Mass, $\mathrm{kg}$

234

60

$\mathrm{Fe}$

Cast

Comp B

13.61
65

44

$\mathrm{Cu}$

\section{Performance Features}

Jet

Initial Tip Velocity, $\mathrm{xm} / \mu \mathrm{sec}$

Effective Tip Velocity at Fuel Pin

Impact, $\mathrm{mm} / \mathrm{usec}$

Average Jet Diameter, mim

$7 \quad>8$

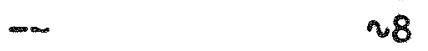

Penetration in Mild Steel, at Optimum

16.5

0.8

Stand-off, m

$0.51-0.76$

$0.51-0.58$

Residual Penetration at Impact with

$-$

20.25

Fuel Pins, m***

* Cone angle refers to the entire included angle measured from cone wall to cone wall.

** HMX is a commonly used explosive in U.S. weapons and has a molecular formula of $\mathrm{C}_{4} \mathrm{H}_{8} \mathrm{~N}_{8} \mathrm{O}_{8}$.

*** This is the depth of steel which could be penetrated by the jet after penetrating the cask walls to reach the fuel pins. 


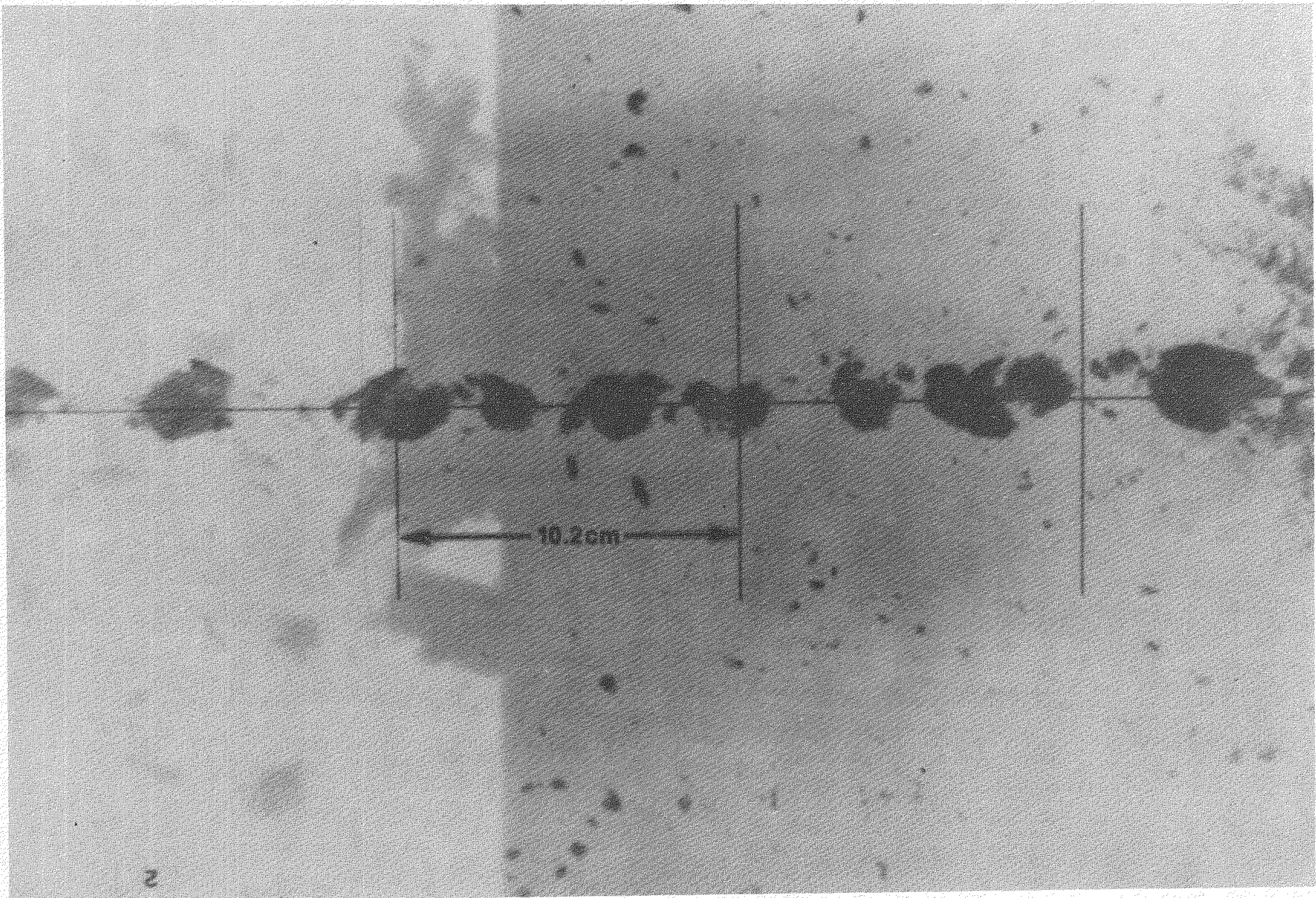

FIGURE 6-1. FLASH X-RAY RADIOGRAPH OF REFERENCE BASIS JET 
Figure 6-2 shows a flash $x$-ray of the precision jet penetrating a row of fuel pin mock-ups formed from $101.6 \mathrm{~mm}$ lengths of $\mathrm{Al}_{2} \mathrm{O}_{3}$ ceramic with glass pellets at the outer ends, housed in thin-walled steel tubing. The jet is also particulated but each particle is a long, narrow cylinder. The particles are well aligned in keeping with the precision of the device.

Both shaped charges produce jets which exhibit a velocity gradient from tip (fastest) to tail, as is true of all such devices. This velocity gradient leads to the formation of a jet whose overall length increases with flight distance or stand-off. At short flight distances the precision jet remains as a continuous rod of solid copper. With increasing flight distance, the ductility limit of the copper is exceeded and the jet separates into a large number of particles (particulates) as shown in Figure 6-2. The character of the reference basis jet at short flight distance is not known with certainty; however, the more limited ductility available in the iron jet and the particle appearance as shown in Figure 6-1 suggest that the reference basis jet particulates at very short flight distances and may be best characterized by individual particles.

The detailed mechanics of penetration of the continuous and particulated jets differ markedly although the resultant penetrations produced may show fewer differences. In either event, the initial contact of the jet with a target leads to the production of strong shock waves originating at the contact interface. The forward shock wave propagates into the target while the rearward shock wave propagates into the oncoming jet tip, or particle. This initial forward shock wave is supported by the continuing motion of the jet material until the pressure is relieved.

In the case of a particle impact the rearward shock wave encountering the rear surface of the particle results in the reflection of a forward moving rarefaction wave which relieves the shock pressure in the particle. This process is visualized schematically in Figure 6-3. In Figure 6-3a we see a flat flyer plate (standing in for a jet particle to simplify the description) about to impact a large, flat-surfaced target of the same material (again for simplicity). In Figure 6-3b the impact has occurred, generating shock waves which move away from the interface in both directions. In the laboratory coordinates shown, the rearward shock moves more slowly 


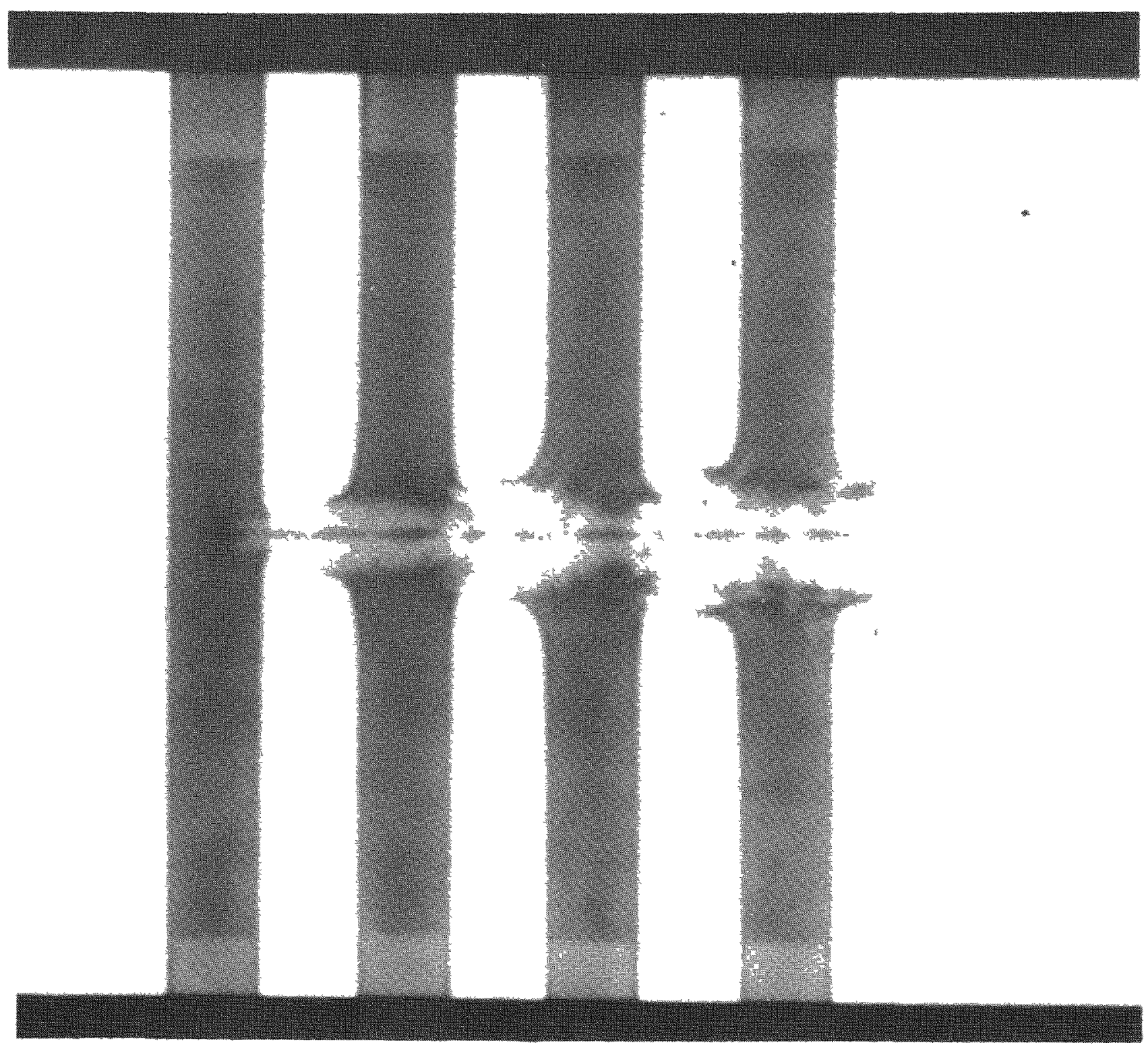

FIGURE 6-2. X-RAY OF JET PENETRATION THROUGH 4-PIN ARRAY 

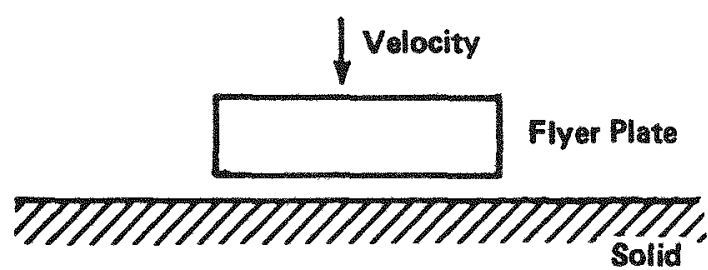

Target
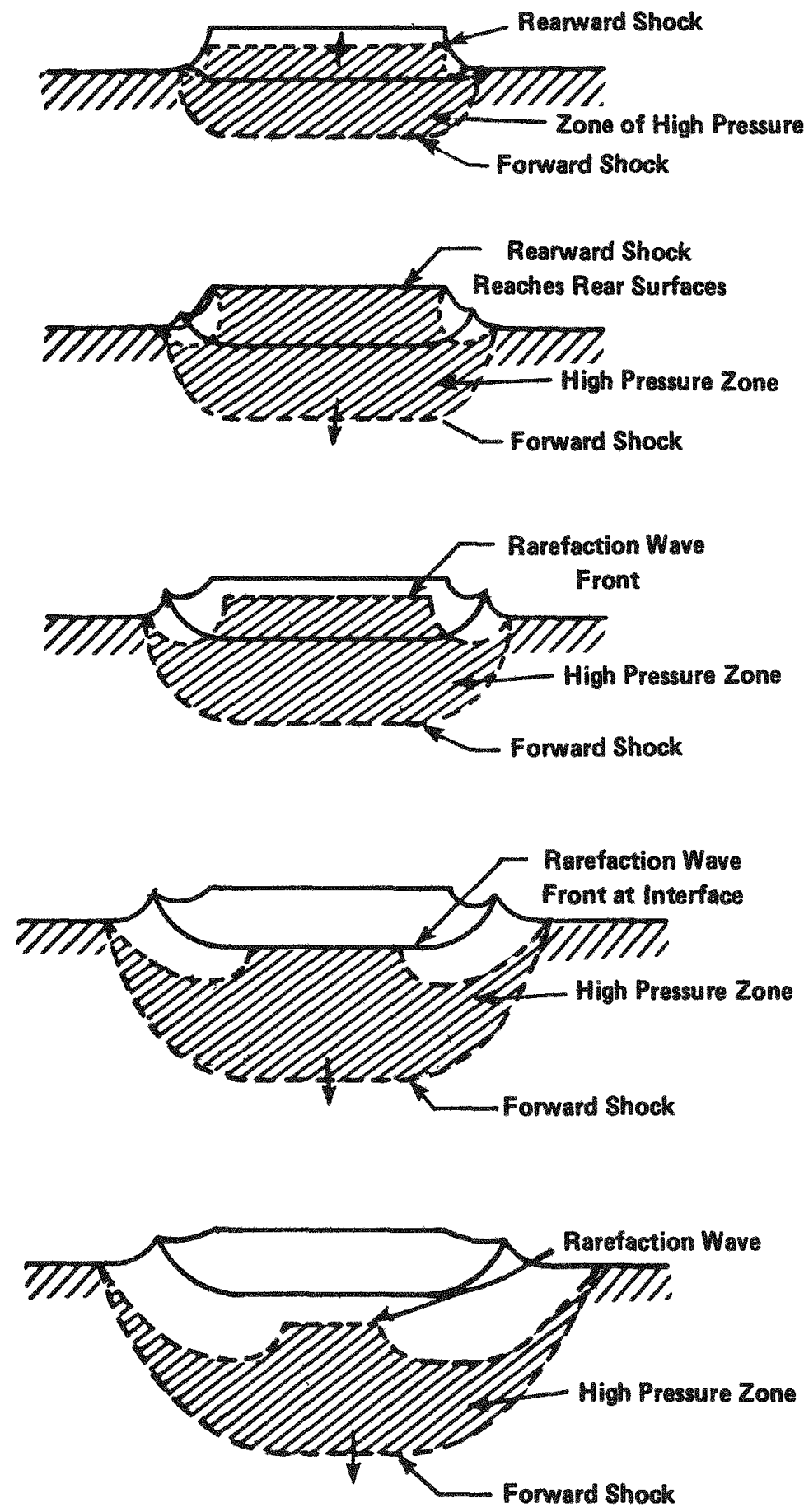

FIGURE 6-3. FLYER IMPACT ON A FLAT TARGET aefore Impact

b. High Pressure Zone Forming

c. High Pressure

Zone Formed

d. High Pressure Zone Moving Into Flyer

e. High Pressure Zone Completely in Target
1. Pressurized Zone Moving Into Target


than the forward shock because it is moving against the incoming flyer material (or mass) velocity. In Figure $6-3 \mathrm{c}$ the rearward shock just reaches the free surface of the flyer. At this point the rearward shock "reflects" as a rarefaction wave which drops the pressure to zero. (A free surface cannot support a pressure in this approximation in which the impact-induced pressures are far greater than the material's strength.) In Figure 6-3d the rarefaction wave is moving into the flyer material. The motion of the rarefaction wave continues across the interface in Figure 6-3e and on into the target in Figure 6-3f. Thus we see that a pressure pulse has been formed which is about twice the original flyer thickness. As we shall see, in the detailed description, the spreading of the forward shock soon dominates the pressures maintained. This is indicated schematically here by the curved portions of the forward shock near the edges of the original flyer where spreading and lowering of the initial pressure is occurring.

In the case of the continuous jet, the initial stages of jet impact are shown, highly schematically, in Figure 6-4. Here we picture a flat-nosed jet about to impact a large flat target in Figure 6-4a. In Figure 6-4b, soon after impact, we see both the forward and rearward shocks moving into the target and jet material respectively. Here, however, due to the small jet diameter, the rarefaction wave fronts from the sides of the jet are aiready apparent due to the relatively smaller jet diameter. In Figure $6-4 c$, the lateral rarefaction fronts have nearly closed on themselves along the jet axis, and in Figure 6-4d the lateral rarefaction waves have cut off the initial high pressure zone. But in this case, due to the continuous supply of new material to the impact zone from the jet, the rarefaction fronts do not reduce the pressure all the way to zero except at the actual free surfaces. Instead, a new "hydrodynamic" pressure zone is formed which includes a maximum at the centerline and gradients outward and upward to the free surfaces as dictated by the flow of material in this zone. In Figure 6-4e we see this process further developed, and the high pressure zone shrinking further. Note that the maximum pressure in the high pressure zone has been decaying from Figure 6-4b onward due to wave spreading effects, so that the high pressure zone is not only shrinking in size, but also in maximum 

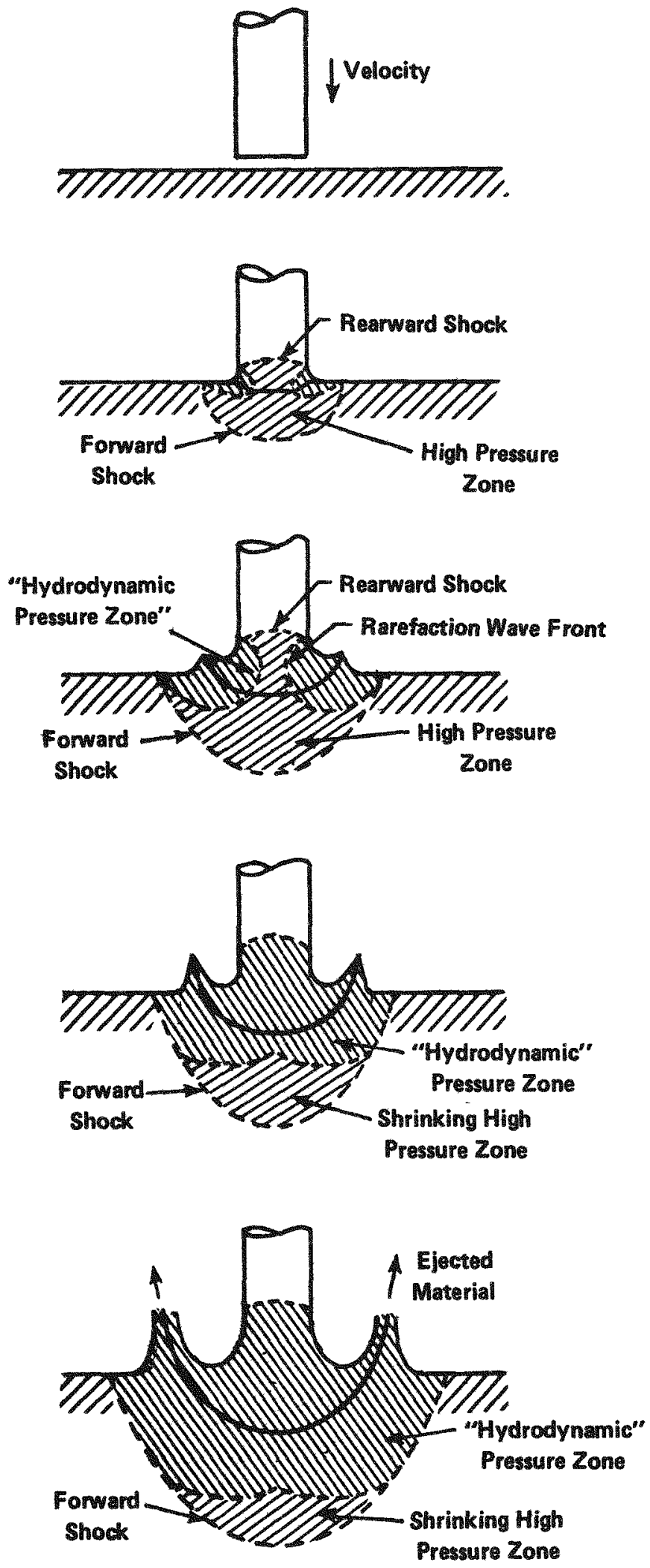

a. Before Impact

b. High Pressure Zone Forming

c. High Pressure Zone Being Cut Off by Lateral Rarefaction Waves, Hydrodynamic Pressure Zone Forming

d. High Pressure Zone Completely in Target and Shrinking

e. High Pressure Zone Shrinking, "Hydrodynamic" zone Continuing to Develop 
pressure. In the end, the maximum pressure in the high pressure zone will simply decay to the "steady state" penetration value where the shock velocity equals the penetration velocity of the jet, and the pressure across the shock is less than the "hydrodynamic" pressure at the interface between the jet and target. The compression of the target material behind the initial shock up to a maximum at the interface takes place isentropically up a pressure gradient dictated by the flow of material in the region.

In the case of fuel pin impact, neither the target nor the jet (or particle) surfaces are planar. Hence the area of contact between the jet (or particle) and the target begins as a (central) point and grows to the jet or particle diameter as the colliding surfaces deform.

For separated jet particles, the initial impact shock wave entering the target and the subsequent mass velocity imparted to the target dominate the penetration mechanism. These motions and associated pressures may drop to essentially zero values before the impact of the next particle produces a new shock and increment of target penetration.

For the continuous jet, the pressures and mass motion produced by the initial shock are gradualiy replaced by more or less steady pressures behind the initial shock wave which are generated by the continued flow of jet material toward the impact interface. This phase of target penetration has been characterized as hydrodynamic. The centerline pressure and penetration verocity at the interface may be determined approximately by application of the Bernoulli equation, yielding for the penetration velocity

$$
u_{p}=v_{j} /\left(1+\sqrt{\frac{\rho_{t}}{\rho_{j}}}\right),
$$

where $V_{j}$ is the jet velocity at impact.

$\rho_{j}$ is the jet density,

$\rho_{t}$ is the target density,

and for the interface pressure,

$$
P=\rho_{t} U_{p}^{2} / 2
$$


The hydrodynamic pressure is much less than the initial impact pressure but for typical jet parameters is still very large in comparision to the strength of any known materials.

Table 6-2 presents a comparison of the initial impact pressures, hydrodynamic pressures, and penetration velocities for a range of jet velocities for both copper and iron jets impacting on $\mathrm{UO}_{2}$ at a density of $10.54 \times 10^{3} \mathrm{~kg} / \mathrm{m}^{3}$. The initial impact pressures were calculated assuming planar impacts using the Hugoniot or shock equations of state $(7,8)$ and the Hugoniot equations for conservation of mass and momentum. (9)

The HEL for unirradiated $\mathrm{UO}_{2}$ was given in reference ${ }^{(7)}$ as 5.7 $\mathrm{GPa}(57 \mathrm{kbar})$. The HEL for irradiated $\mathrm{UO}_{2}$ was assumed to be of the same order of magnitude. This pressure is exceeded, by a factor of nearly 60 for the highest pressures shown, and still greatly exceeded down to the lowest initial impact pressures shown. Thus volumes appreciably greater than the jet cross section times its length through the fuel pins will exceed the HEL for both jets considered.

In the following analysis, a considerabie number of assumptions were necessary due to the inherentiy three dimensional nature of a jet impact on a fuel pin. Such three dimensional analyses are currently beyond the state of the art for even the largest hydrodynamic finite element computer codes. The analyses have been guided, however, by relatable two-dimensional analyses as available.

\section{Analys is of Reference Basis Threat}

An approximate analysis of the interaction of a particle from the reference basis threat with a single fuel pin was conducted. The analysis used the Hugoniot equations of state for $\mathrm{UO}_{2}{ }^{(7)}$ and iron ${ }^{(8)}$. The initial impact pressures, particle or mass velocities, and shock velocities along the centerline of impact were calculated assuming planar impact conditions. off-axis conditions were estimated using a combination of judgment, graphical and analytical procedures. The analys is of the many complex phenomena occurring is incomplete and several of the features to be depicted may be quantitatively in error, but qualitatively, the features are generally expected to occur as shown. 
TABLE 6-2. JET PENETRATION PARAMETERS

\begin{tabular}{|c|c|c|c|c|c|c|}
\hline \multirow[b]{2}{*}{$\begin{array}{l}\text { Jet Velocity } \\
\mathrm{mm} / \mu \mathrm{sec}\end{array}$} & \multicolumn{2}{|c|}{ Initial Impact } & \multicolumn{2}{|c|}{ Hydrodynamic Pressure } & \multicolumn{2}{|c|}{ Penetration Velocity } \\
\hline & $\begin{array}{c}\mathrm{Cu} \text { jet } \\
\mathrm{GPd}\end{array}$ & $\begin{array}{c}\text { Fe jet } \\
\text { GPa } \\
\end{array}$ & $\begin{array}{c}\text { Cu jet } \\
\mathrm{GPa}\end{array}$ & $\begin{array}{c}\text { Fe Jet } \\
\text { GPa } \\
\end{array}$ & $\begin{array}{r}\text { Cu Jet } \\
m m / 4 s e c\end{array}$ & $\begin{array}{r}\text { Fe Jet } \\
\mathrm{mm} / \mu \mathrm{sec}\end{array}$ \\
\hline 1.5 & 34.5 & 32.0 & 2.73 & 2.40 & .72 & .69 \\
\hline 2.22 & 55.0 & 52.0 & 6.0 & 5.72 & 1.07 & 1.03 \\
\hline 4.00 & 120.0 & 111.0 & 19.4 & 17.1 & 1.92 & 1.85 \\
\hline 7.00 & 274.0 & 262.0 & 59.4 & 52.2 & 3.36 & 3.24 \\
\hline 8.0 & 342.0 & 325.0 & 77.6 & 68.2 & 3.84 & 3.71 \\
\hline
\end{tabular}


As shown in Figure 6-5a, the condition selected for analysis was the impact of an initially spherical particle of iron $16.5 \mathrm{~mm}$ in diameter, traveling at $7.0 \mathrm{~km} / \mathrm{sec}$ on the centerline of a $10 \mathrm{~mm}$ diameter pin of $\mathrm{UO}_{2}$. The cladding on the pin was ignored as an unnecessary complication.

As shown in Figure 6-5b, the combination of distortions of the initial impact interface and growth of the impact area gave rise to a forward shock wave moving into the pin which had a near-circular section along the length of the pin at times up to $\sim 0.6 \mu \mathrm{sec}$. At about this time, the shock velocities in both the particle and pin exceeded the radial expansion velocity of the impact area and the shocks began moving away from the edge of the impact area. The initial impact pressure of $262 \mathrm{GPa}$ was assumed to be maintained up to this time, which is not strictly true. As the shocks moved away from the edge of the impact area, they left behind a region of high pressure facing a free surface, which gave rise to the rapid ejection of material laterally and rearward from this region as shown schematically in Figure $6-5 c$ and $d$. The forward shock moving into the pin was expanding in frontal area and hence the pressure must decay. The numerical calculations of Mok ${ }^{(10)}$ suggest for a similar but not identical case that the rate of pressure decay in the early stages should be proportional to the inverse first power of the radius. Others (11), however, and Mok in the later stages, suggest that the rate of pressure decay should more nearly approximate the inverse second power of the shock radius. The range of pressures shown in Figures $6-5 c$ and $d$ are based on these two attenuation laws. As shown, even the minimum predicted shock pressures still exceed the HEL by an order of magnitude at $2.2 \mu s e c$ after impact. By this time, a considerable segment of the pin rear surface has been set in motion by the forward shock wave reflection, leading to a high probability of ejecting sufficient material off axis to damage adjacent pins.

The subsequent shock wave attentuation as it progresses up the fuel pin away from the impact site will be governed primarily by the ingress of rarefaction waves from the free surface of the fuel pin. The estimated extent of 
Reference Jet

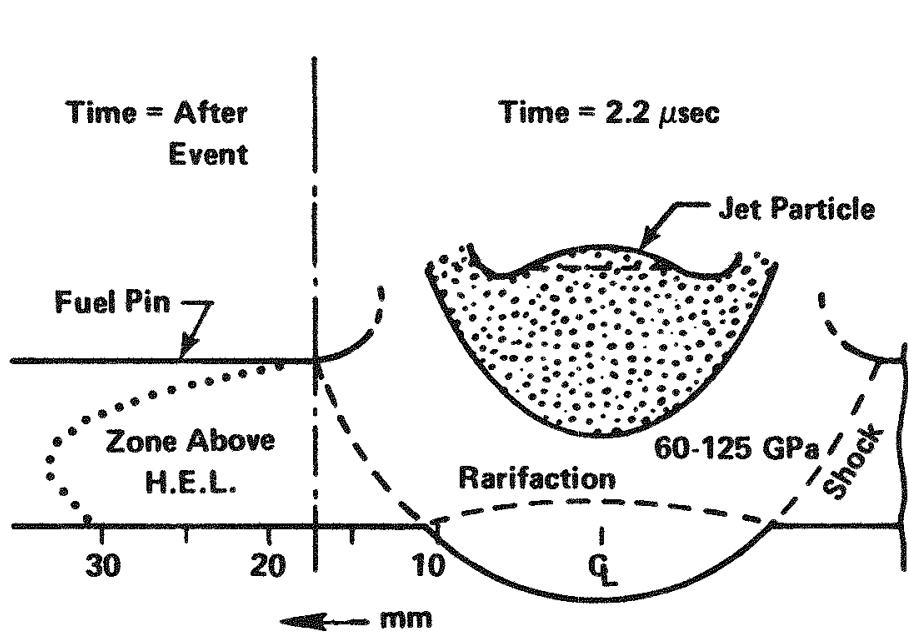

b.

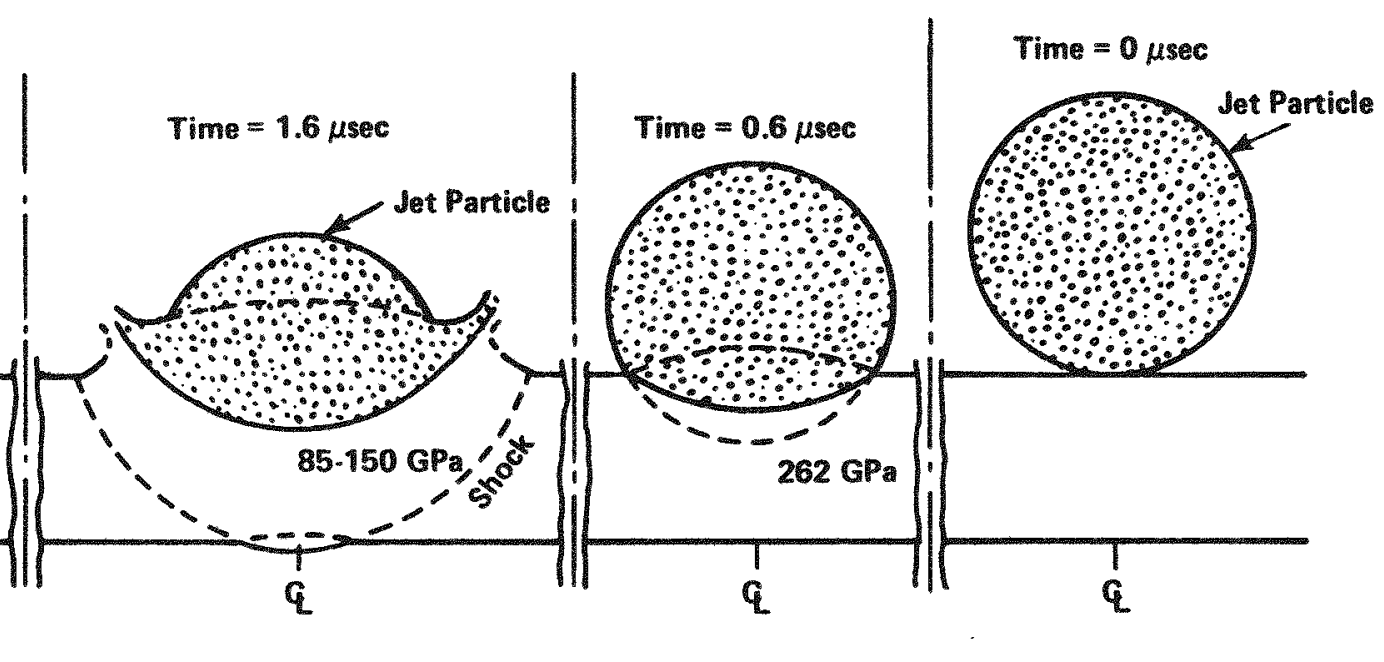

FIGURE 6-5. REFERENCE JET PARTICLE INTERACTION WITH FUEL PIN 
the volume* up the fuel pin which reached pressures above the HEL is shown in Figure $6-5 \mathrm{e}$. The results of this analysis will be used in a later section to develop a ratio of volumes above the HEL for the reference and precision threat cases.

\section{Analysis of Subscale Precision Threat}

The approximate analysis of the precision jet was performed using the same methodology as used for the reference $M-3$ jet. A centerline impact on a $10 \mathrm{~mm}$ pin was assumed of a jet with an initially hemispherical nose moving at $8 \mathrm{~km} / \mathrm{sec}$ and a continuous length of $0.8-\mathrm{mm}$-diameter copper jet following at uniform velocity. However, in this case, the shock separation equivalent to that at 0.6 microsecond for the reference jet was found to occur at a time of 0.051 microsecond when the area in contact was about equal to the jet area, and penetration had progressed only $0.21 \mathrm{~mm}$.

As shown in Table 6-2, the impact pressure up to this time is taken to be $342 \mathrm{GPa}$. As the forward shock moved ahead of the contact interface, material ejection began, as did decay of the forward shock pressure. Figure 6-6a shows the approximate geometry at 0.14 microsecond after impact. The pressure at the shock front, assuming inverse first-power decay has dropped to $136 \mathrm{GPa}$, and the pressure at the interface has decayed to the quasi-steady state interface pressure calculated on the basis of incompressible hydrodynamic flow at $78 \mathrm{GPa}$. As the forward shock continues to expand and decay in pressure, its velocity also decays. At a time of about 0.74 microsecond, as shown in Figure 6-6b, the forward shock has decayed to about $37 \mathrm{GPa}$ on the jet centerline. At this pressure, the $\mathrm{UO}_{2}$ equation of state indicates that the shock velocity is $\sim 3.8 \mathrm{~mm} / \mathrm{microsecond,} \mathrm{equal}$ to the hydrodynamic penetration velocity as given in Table 6-2. This

* The dashed line outlining this volume represents the judgment of one of the authors (Trott). Dr. Trott has 15 years of experience with shock-related phenomena. 


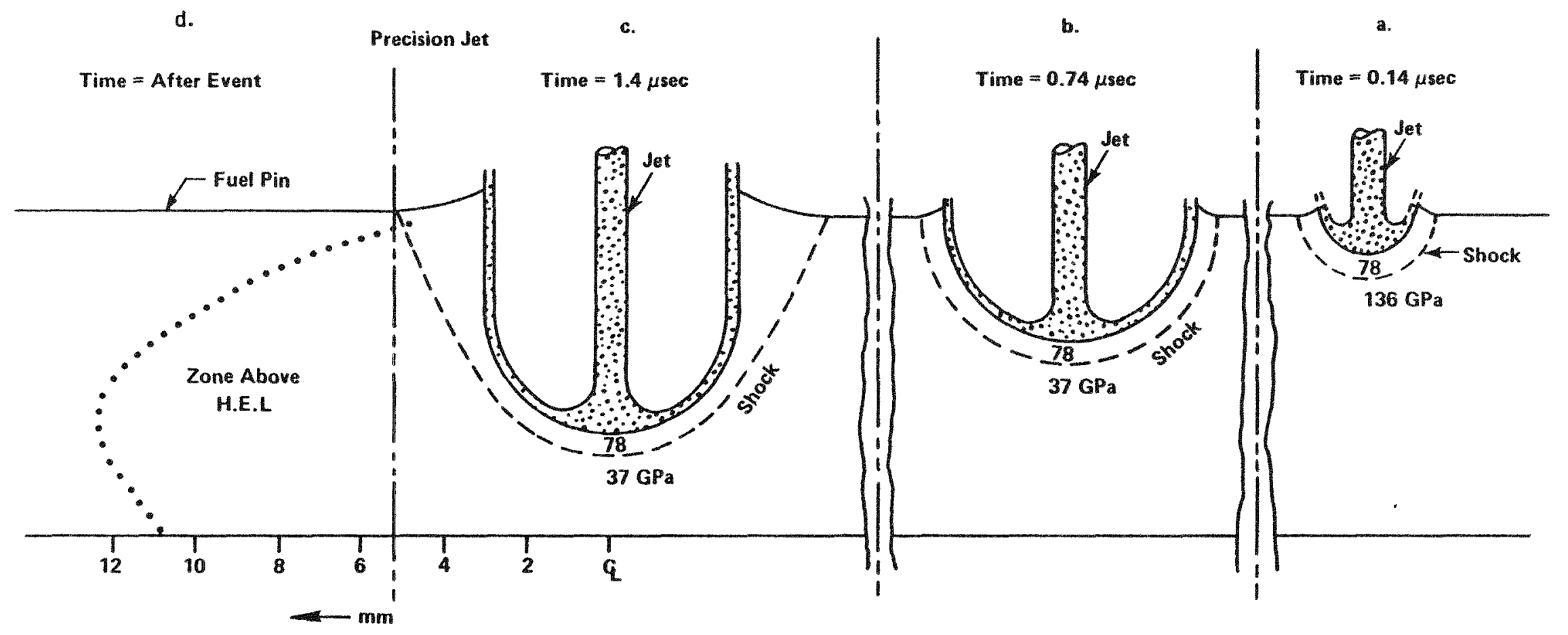

FIGURE 6-6. SUBSCALE PRECISION JET INTERACTION WITH FUEL PIN 
penetration velocity is the velocity of the interface between jet and fuel pin. Thus a new quasi-steady state situation is established. The forward shock continues along the centerline at $37 \mathrm{GPa}$ spaced off an approximately constant distance in front of the penetrating interface. As before, the lateral flow of the target material to form the cavity takes place behind this shock, in the pressurized zone. Assuming a hemispherical cavity development, as frequently observed in hypervelocity impacts, the radius of the developing interface is found to be about $3 \mathrm{~mm}$, in good agreement with the cavity diameter visible in the original $x$-ray of which Figure 6-2 is a reproduction. It should be noted that in Figure $6-2$, penetration is shown into $\mathrm{Al}_{2} \mathrm{O}_{3}$ rather than $\mathrm{UO}_{2}$.

As shown in Figure 6-6c for 1.4 microsec. after impact, the quasisteady penetration continues but the lateral shock near the initial impact surface continues to spread away from the cavity and decay in amplitude. The rate of this decay, which is neither cylindrical nor spherical is difficult to estimate with confidence.

In Figure 6-6d, the zone of pin material which was at any time during the impact process above the HEL was estimated to lie along the dotted line. This location is based mainly on engineering judgment but is also supported in part by the post shot appearance of the actual pins.

\section{Application to Scaling}

In addition to the foregoing, somewhat idealizec analyses, there are several effects to be considered in the development of a scaling relationship between the reference basis incident and the scaled experiments. These are all parts of problems related to variations in the jet damage pctential along the entire path of the jet through the cask.

There are two major variables which interac: in the process of jet penetration. One is the jet, and the other is the target. The jet is a long, and stretching stream of solid material and/or particles which have an initial tip velocity, and a graoient of decreasing velocity along the jet length to the effective tail of the jet. 
The most important parameter of the target material appears, from hydrodynamic theory, to be the mass per unit length of path. For solid material, this is equivalent to the material density. As the velocity of the impacting jet decreases, the strength of the target material becomes increasingly important. The target strength effect may terminate further penetration of the jet when there is still a finite length of a relatively low velocity material remaining in the jet.

During the jet-target interaction, each increment of the jet contacting the target is consumed in penetrating an increment of the target. Thus, the leading particle or effective tip of the jet entering the interior of a shipping cask will have lower velocity than the initial jet tip, leading to the production of lower impact and hydrodynamic pressures on the fuel pins than the original jet tip would have produced. For the same reason, the last fuel pin impacted in a fuel element will be struck by a jet particle having lower velocity than the first pin struck.

The importance of the above effects in the development of a scaling relationship is not possible to evaluate with certainty. Aside from the purely analytical difficulties, if all of the interaction parameters and material properties were known (which they are not), a great deal more knowledge regarding the mass and velocity distribution of the jet material along its length for both the precision scaled jet and the reference basis jet would be needed. Hence the scaling attempted here must necessarily include rather broad uncertainty bars.

To produce an estimated scaling relationship, we have tacitly assumed that the degradation of the jet impacting velocity produced by penetration of the sub-sized cask wall used in the experiments is similar to that which will occur in the reference basis event. Further, we have assumed that the volumes of fuel pin affected will scale linearly under these conditions. Another related assumption is that although a smaller mass of fine particle release is expected from the last pin impacted than from the first the damage is assumed to scale proportionately for the two threats considered, such that the ratio of radioactive masses fractured will remain the same and that the particle size distributions resulting from fracturing will remain the same. 
Another necessary assumption is that the fraction of fractured radioactive material released from actual and model casks remains the same. But before the scaling estimate can be considered completely valid, additional testina of the actual fracture and release behavior of the full scale event are needed.

From the validation tests performed on this program we learned that the precision jet does not produce debris from impacted single pins in each row of an array which is capable of inflicting meaningful damage (fracture) of adjacent fuel pins not actually impacted by the jet. Hence the estimated volume fractured in the foregoing analysis of a jet interaction with a single pin can be taken as representative of the jet interaction with each pin of the fuel element array, subject to other assumptions of this attempt at scaling.

No similar direct data regarding damage to adjacent fuel pins not actually impacted by the reference-basis jet yet exists. However, the analys is of the interaction between a single pin and reference basis jet particle showed that the primary forward shock waves emergent at the pin side and rear surfaces have a much higher pressure amplitude than in the case of the precision jet-pin interaction. Hence, damage to adjacent pins by the flying debris from a reference basis jet particle interaction with a single pin becomes possible.

Table 6-3 shows the estimated relative importance of various mechanisms of jet or particle interaction with a fuel pin, based on the foregoing analy'ses.

Table 6-4 provides a summary of the form, and numerical values assigned for the scaling relationship between the precision jet (experimental case) and the reference basis event. The scaling relation has been divided into two terms for the single pin interaction. Each term may be thought of as an estimate of the fuel pin length raised above the HEL by a particular mechanism. The first term is taken as proportional to the jet diameter, because this relates directly to the pin length affected directly by the jet-pin interaction. The second term is, of course, related to the jet-pin interaction, but its magnitude is more directly 
TABLE 6-3, MECHANISMS IMPORTANT TO SCALING

\begin{tabular}{|c|c|c|}
\hline \multirow[b]{2}{*}{ Mechanism } & \multicolumn{2}{|c|}{ Relative Importance } \\
\hline & $\begin{array}{l}\text { Precision } \\
\text { Jet }\end{array}$ & $\begin{array}{l}\text { Reference } \\
\text { Jet }\end{array}$ \\
\hline Initial impact & Sma 11 & Major \\
\hline Hydrodynamic flow & Major & Minor \\
\hline \multicolumn{3}{|l|}{ Shock attenuation } \\
\hline By spherical expansion & Major & Minor \\
\hline $\begin{array}{l}\text { By release at pin free } \\
\text { surfaces }\end{array}$ & Less & Major \\
\hline Effect of particulation & Less & More \\
\hline
\end{tabular}


TABLE 6-4. SCALING SUMMARY

\begin{tabular}{|c|c|c|}
\hline & $\begin{array}{l}\text { Precision } \\
\text { Jet }\end{array}$ & $\begin{array}{l}\text { Reference } \\
\text { Jet }\end{array}$ \\
\hline \multicolumn{3}{|l|}{$\begin{array}{l}\text { Single pin volume }=\left(\begin{array}{ll}K_{1} & D_{\text {jet }}+ \\
K_{2} D_{\text {pin }}\end{array}\right) D^{2} \text { pin }\end{array}$} \\
\hline \multicolumn{3}{|l|}{ Selected values } \\
\hline$k_{1}$ & 7.5 & 1.7 \\
\hline$k_{2}$ & 1.6 & 3.2 \\
\hline Jet diam, $D_{\text {jet }}(\mathrm{mm})$ & 0.8 & 17.4 \\
\hline Fuel pin diam, $D_{p i n}(\mathrm{~mm})$ & 10.0 & 10.0 \\
\hline Single pin volume $\left(\mathrm{mm}^{3}\right)$ & 2200.0 & 6160.0 \\
\hline Additional pins & 0 & $2\left(1.5 D_{j e t}\right) D_{p i n}^{2}$ \\
\hline TOTAL PIN VOLUME $\left(\mathrm{mm}^{3}\right)$ & 2200.0 & 11400.0 \\
\hline Relative volume & 1 & $\begin{array}{ll}5.2 & -0 \\
+13.0\end{array}$ \\
\hline
\end{tabular}


determined by the pin diameter. The second term is an effort to express the indication that the shock amplitude decay outside the zone of direct jet-pin interaction is governed primarily by the release of the pressure at the free surfaces of the pin. The factor $\pi / 4$ necessary to make the indicated products pin volumes, has been omitted because it would cancel out in the final ratioing of the volumes anyway.

The values selected for the constants $K_{1}$ and $K_{2}$ shown in Table 6-4 for the two jets considered were based on the foregoing analysis and engineering jugment. The values selected for $k_{1}$ were taken as the ratio of the length of fuel pin consumed by the primary interaction of the jet to particle or jet diameter as estimated from the analysis as shown in Figures 6-5d and 6-6c, respectively. The values selected for $k_{2}$ were taken as the ratio of the length of fuel pin consumed during decay of the induced shock wave to the HEL to the pin diameter. Values for $K_{2}$ were estimated from the analysis as shown in Figures 6-5e and 6-6d for the precision and reference jet respectively. Use of these values, together with the jet and pin diameters given in the single pin volume formula leads to the single pin volumes shown. As described earlier, no additional pins beyond the primary pin impacted were appreciably affected by the precision jet. Some additional pin volume is expected to be affected (raised above the HEL) by the reference basis threat however, as indicated in Table 6-4. The final scaling value was obtained by dividing the total pin volume affected by the reference basis jet by the total pin volume for the precision jet. The indicated uncertainty, $-0,+13.0$ is meant to convey the particular uncertainty associated with deviations from straightness of the reference basis jet. As described earlier, there are many uncertainties associated with the validity of this estimated scaling factor, and it should be regarded as a best estimate which may be adjusted by results from a recent DOE-sponsored test of an M- 3 and an actual cask containing unirradiated fuel pins. 
CHAPTER 7

\section{IMPLICATIONS OF RESULTS}

The objectives of the shipping cask sabotage source term investigations were to characterize the source terms resulting from both direct and indirect violations of spent fuel shipping casks. In the direct violation experiments, a small shaped charge was fired at a model cask, and some spent fuel was released. In the indirect (secondary) violation experiments, one model cask was attacked with a platter charge and another with an air blast. Zero release fraction was calculated for each case. No source term was characterized from these experiments. The source term from a direct violation has been measured in four subscale experiments using a "full cask" configuration. Data from these tests indicated that the initial aerosol concentration of uranium in the sampling chamber ranged from 50 to $500 \mathrm{\mu g} / \mathrm{l}$ with the most probable conservative value being between 50 and 200. In order to be more conservative, we will use an airborne uranium concentration of $500 \mathrm{\mu g} / \mathrm{l}$ in the calculations in this chapter. The total airborne release from a full scale cask containing one $15 \times 15$ spent PWR assembly is calculated below:

$$
\begin{aligned}
& \left(5 \times 10^{-4} \mathrm{~g} / \mathrm{l} / \text { row of pins }\right)(230 \mathrm{l}) \text { (15 rows of pins/assembly) } \\
& (5.2)=8.97 \mathrm{~g}
\end{aligned}
$$

where $230 \mathrm{l}$ is the volume of the sampling chamber and 5.2 is the scaling factor developed in Chapter 6.

For comparison to other studies it is useful to calculate the respirable release fraction, that is the ratio of the mass of uranium released in respirable form to the total mass of uranium in one PWR element. To make this calculation conservative also, we have assumed that all of the airborne uranium is respirable. The respirable release fraction is

$$
8.97 \mathrm{~g}: 4.7 \times 10^{5} \mathrm{~g} / \text { assembly }=1.91 \times 10^{-5} \text {. }
$$


Note that this analys is applies to a cask containing a single PWR fuel assembly. In casks designed to carry more than one PWR assembly, the assemblies are usually arranged so that it would be difficult for the path of a single shaped charge to pass through all of the assemblies. Furthermore, it is highly unlikely that a shaped charge jet could pass completely through a multi-assembly cask. Thus the respirable release fraction for a multi-assembly cask would be no larger than that for a single assembly cask. 


\section{REFERENCES}

1. Schmidt, E.W., Walters, M. A., Trott, B. D., "Interim Report on Shipping Cask Sabotage Source Term Investigation", Battelle's Columbus Laboratories (November, 1979).

2. Schmidt, E.W., Walters, M. A., Trott, B. D., "Topical Report on Shipping Cask Sabotage Source Term Investigation", Battelle's Columbus Laboratories (November, 1981).

3. Mattsen, C., Memo to NRC files (January 3, 1979).

4. Wilkins, M. L., in "Calculation of Elastic Plastic Flow", in Methods in Computational Physics, Vol. 3, Edited by Alder, B., et al., Academic Press, (1964):

5. Backofen, J. E., Jr., "Rapid Disposal of Buried Bombs Through Excavation and Destruction by Shaped Charges", NEODF 2-10, for the Naval Explosive Ordnance Disposal Facility, Indian Head, MD, by Battelle's Columbus Laboratories (September, 1977).

6. Radiograph courtesy of Dr. R. P. Sandoval, Sandia Labs., Albuquerque, New Mexico.

7. Isaacson, L., "Shock Compression and Hugoniot Elastic Limit Data for Uranium Dioxide", Engineering Design File Report, Serial No. I WFRP-152, EG\&G Idaho, Inc., (March 5, 1980).

8. Van Thie1, M., "Compendium of Shockwave Data", UCEL-50108, Lawrence Radiation Laboratory, (June, 1966).

9. See, for example, McQueen, R. G., et a1., in "High Velocity Impact Phenomena", edited by R. Kinslow, Academic Press, New York and London, 1970.

10. Mok, C. H., "Effects of Solid Strength on the Propagation and Attenuation of Spherical Plane Shock Waves", J. Appl. Phys., 39, p. 2072, (March, 1968).

11. See, for example, Torrik, P. J., and Prater, R.J.F., "A Simple Model for the Shock Wave Induced by High Speed Impact", J. Spacecraft, 9 , p. 13, (January, 1972). 


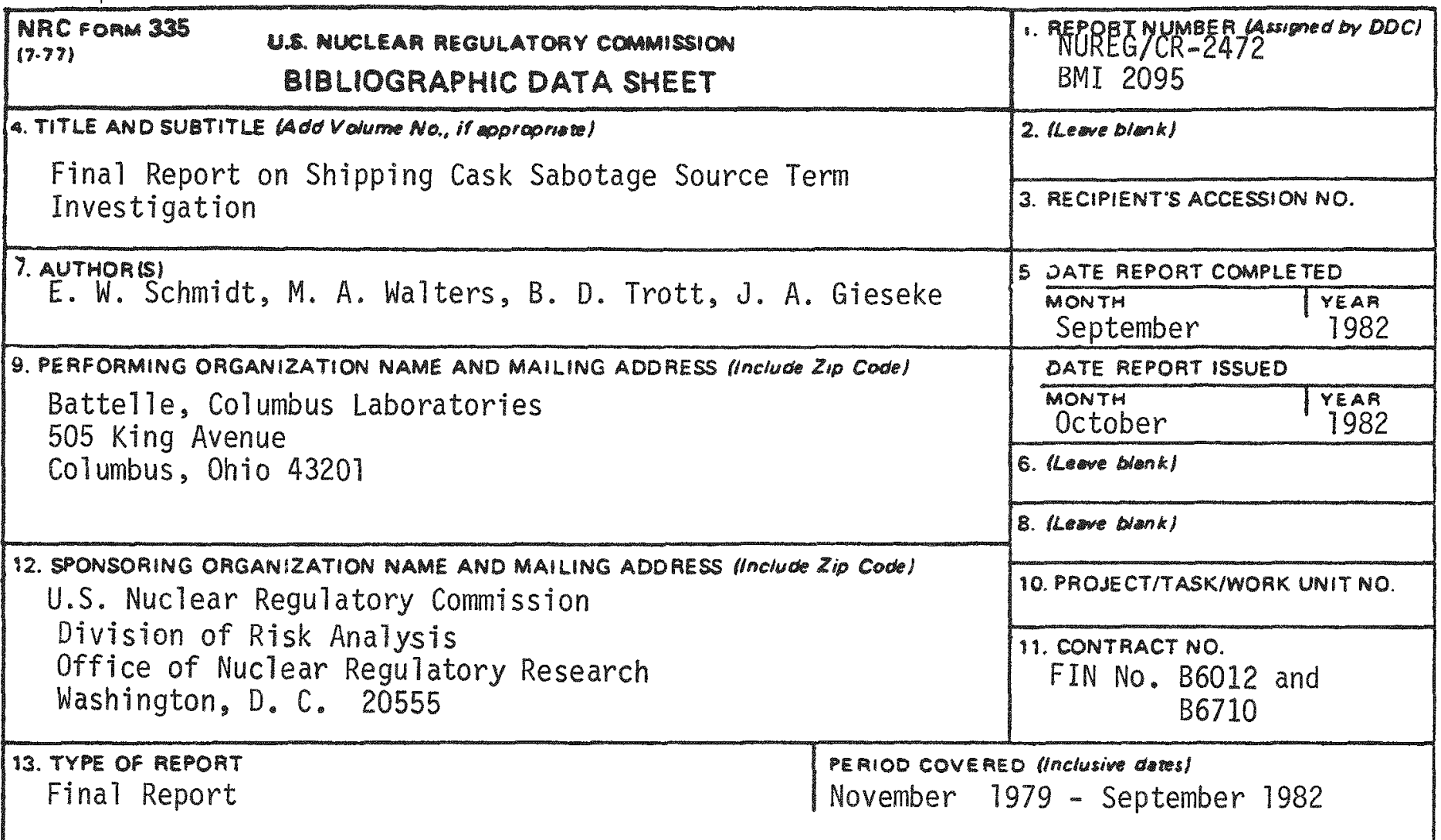

15. SUPPLEMENTARY NOTES

14. (benk)

16. ARSTRACT (200 wOrJs OP

A need existed to estimate the source term resulting from a sabotage attack on a spent nuclear fuel shipping cask. An experimental program sponsored by the U.S. NRC and conducted at Battelle's Columbus Laboratories was designed to meet that need. In the program a precision shaped charge was fired through a subscale model cask loaded with segments of spent PWR fuel rods and the radioactive material released was analyzed. This report describes these experiments and presents their results.

Sabotage

Radiological Source Term

Spent Fuel

Transportation

170. IDENTIFIERS/OPEN-ENDED TERMS 